\title{
THE DEVELOPMENT OF A HEATING STOVE \\ FOR THE KALAM REGION \\ OF PAKISTAN
}
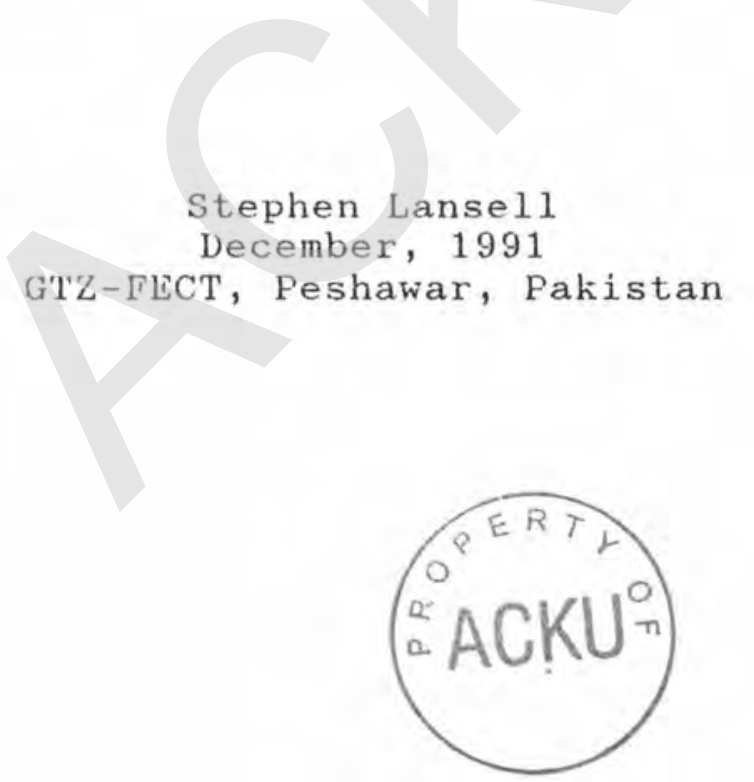


\section{NDEX}

1. Introduction \& llistory |

2. Design Criteria 2

2.1 Smoke 2

2.2 Price 2

2.3 Fuel Consumption

2.4 Cooking Ability 2

2.5 lleating Ability 3

2.6 Useability 3

3. Laboratory Testing 4

3.1 Smoke Testing 4

3.2 Cost Estimation 5

3.3 Cooking Ability 5

3.4 lleating Ability 5

3.5 Efficiency of Combustion 5

3.6 Deformability \& Blockability 6

4. Field Testing i

4.1 llousehold Selection Criteria 7

4.2 Field Testing Methodology 7

5. The Devices 8

5.1 The Bellers 9

5.2 The Zahers 16

5.3 The Jurgens $\quad 20$

5.4 The Lexcens $\quad 25$

5.5 The Baris 26

5.6 The Double Chimney Water Tanks 27

6. Device Production 29

7. Conclusions \& Recommendations 30

7.1 Device Testing $\quad 30$

7,2 Vevice Vesign 31

8. References 34

9. Appendices

1 Laboratory Test Summary Results

2 Filter paper tests

3 The questionnaire used in phase III of the field testing 


\section{Introduction \& History}

Since 1984 the fuel efficient cooking technologies project (FECT-GTZ) has developed many potentially fuel saving devices. The main fruits of this development work has been the 'Multipot Stove' and the 'Bakery Oven'.

The credit for initiating the co-operative effort between GTz and KIDP in the area of heating devices must go to Mr lqbal llussain of K1DP who in his ceaseless efforts to reduce the destruction of the forests in the kalam region sought permission in late 1989 from his CTA at that time, Mr llermann Warth, to make contact with GTZ regarding the introduction of an improved stove to the operational area of KIDP. It was soon realized that much work would be required on both sides if a successful development and dissemination was going to take place. By early 1990 it was decided to perform a "full scale household survey with detailed questionnaires", but this was eventually scaled down to a "Rapid Rural Appraisal" (Ref 1, Page 18) which resulted in the production of the report entitled "Assessment Study Concerning the Potential for Starting Domestic Fuel Saving Activities by KIDF" in June of 1990 .

Research and meetings continued and eventually in ear1y December of 1990 the report entitled "A Proposal for Co-operation between FECT \& KIDP" was produced. Unfortunately at that crucial time the CTAs of KIDP, llermann \& Dietlinde Warth were replaced by Mr. Christoff Duerr, and then the CTA of FECT went on leave and was replaced by $\mathrm{Mr}$. Jurgen Usinger who had enormous input into the research, and is responsible for the majority of the research procedures introduced in this report. Understandably the course of the co-operation changed significantly under his guidance.

The problems regarding changing CTAs were then further compounded by the Iraqi Gulf Crisis which resulted in a ban on foreigners entering the liefugee Camps, and hence necessitated the movement of the smoke and heat testing room to the FECT office in University Town.

Defore the end of the Gulf Crisis, Jurgen Usinger returned to Germany, the Testaterm Gas Analyzer broke down and after another month or so Cornie lluizenga returned and drastically changed the course of the co-operation again. A new "Proposal for Co-Operation between FECT \& KIDP (Versions $2 \& 3$ )" was commissioned and produced by late April, 1991. This was submitted to KIDF for approval, but subsequent to a meeting held on the 24 th of April it was decided to discontinue the co-operation.

As can be seen from version 2 of the "Proposal for Co-operation between FECT \& KIDP", much was planned to happen in the areas of device development, production and dissemination. Unfortunately the last area of co-operation was never developed and investigation into device production had only just begun, nevertheless much was learnt in the area of heating stove research and development and this report attempts to summarize all the information gained in that area. 


\section{Design Criteria}

Establishing the stove design criteria is a very important and often underestimated step in the process of developing an appropriate stove for a target population. Although more consideration could have been given to the heart felt needs of the people, it is fair to say that under the circumstances this step was given due consideration by both sides. It was only on the co-operation side that difficulties arose despite numerous concerted efforts to produce a concise prioritized list of design criteria that everyone agreed to. In version 2 of the "Proposal for Co-Operation between FECT \& KIDP" it was attempted to produce a design criteria list that could be agreed on, but agreement was never reached due to dissolution of the co-operation. This list is now reproduced here in part to give the reader an idea of the design criteria that were actually used in designing various devices, Referrals to minutes of meetings are given in brackets.

2.1 Smoke. Their first priority is to have stoves which produce no, or at least less smoke (Pt2,80ct90). The main emphasis is to be put on the production of smokeless stoves (Pt5,4Dec90). The exposure of the people to the bad effects of smoke should be bought to a level in accordance with European working standards (Pt1,20Dec90). It is assumed that smoke leakage is due to technical factors and not caused by misoperation (Pt8,201ec50).

2.2 Price. It can be expected that people are ready to pay a higher price for a stove so long as they can easily compare a stove for $250 k$ with a lifetime of 3 years, to a stove for 150 Rs with a 1 year lifetine (Pt3,80ct1990). Durability is appreciated. The price of the improved stove $w i l l$ be $150 \%$ for the traditional one in the same gauge material. FECT will recommend a thicker gauge which might take the price above $150 \%$, but this can be justified to the people (Pt3,20Dec90 \& Pt10,29Jan91). The stove should be durable (Nintemann, 80ct90).

2.3 Fuel Consumption. If possible the fuel consumption in the device should be reduced, however since better smoke removal and fuel efficiency are technically contradictory to some extent, it should be assumed that the improved stove will not dramatically increase the fuel consumption (Pt8,20Dec90). The target population will also appreciate it if they can save money and time in procuring firewood. They are aware of the high input required at the moment, but there is not yet a pressing need to reduce consumption since obtaining firewood is not too difficult and expensive (Pt2,80ct90). The economy of wood consumption is not an incentive here as it is free of cost (Pt4,4Dec90).

In Bahrain more emphasis should be put on the production of fuel efficient stoves since the people pay for the wood and are ready to chop the wood into small pieces (Pt5, 4Dec 90$)$.

2.4 Cooking Ability. The developed device should be more efficient at cooking than the device it is designed to replace $(2.3 .5$, Ref 2$)$. The devices developed by FECT should have combined cooking and heating facilities. Emphasis should be more on cooking rather than heating (Pt4,20Dec90). 
2.5 lleating Ability. The Kalamis have no window panes in the windows due to purdah and security reasons. For light they keep the doors open resulting in a huge amount of heat loss. This problem should be studied in detail. Ways and means should be devised to tackle the problem (Pt13,4Dec90). The stove shall keep the heat for along time (Nintemann,80ct90).

2.6 Useability. The new devices developed by FECT should be socially and economically acceptable to the people of Kalam (Pt2,20Dec90). The devices developed by FECT should be able to accommodate large pieces of wood for burning which are continuously fed into the combustion chamber (Ref 6). This saves having to cut the wood into small pieces. Efforts should be made to use it with the door open if possible (Pt6,20Dec90). Flaps and dampers should be easy to operate and understandable in the new device (Pt9,20Dec90). Cleaning of the devices should be as easy as possible (Pt10,20Dec90). It should save time, not require a high user labor input, be portable and appropriate for the local pot sizes (Nintemann, 80ct90). It must accommodate a Tawa.

It was decided that "water heaters would be introduced later as an optional extra" (Pt7,20Dec90), but when they are that "ways and means be devised for slowing down the corrosion of water heaters" (Pt7,4Dec90). "The water container around the chimney shall be offered, but most people will not see the need of it since they can have a pot for hot water on the stove anytime. The advantage of better usage of energy, and better transfer of heat to the room will not be realized easily. Furthermore the cost factor will affect acceptance adversely" (Pt4,8thoct1990).

"The heating (only) stoves should not be given priority as they are only installed in llujra, which are scarcely used" (Pt2,4Dec90). Furthermore "...they are not seen as causing problems and used much less than kitchen stoves" (Pt4,80ct90). "The idea of combining the heating stove as used in llujras with a facility for cooking should not be followed further since people don't want to cook in their llujras" (Pt1,80ct90). 


\section{Laboratory Testing}

This is possibly the area where the most new ground was broken in the field of heating stove testing particularly with regard to smoke emission testing, exhaust gas analysis and in obtaining Power versus PIIU curves. It was also the area most severely affected by the intervention of the Iraqi Gulf Crisis necessitating the removal of the laboratory from the purpose built room at Kacha Gari to a makeshift laboratory in the FECT offices at University Town. Much credit for making the new test procedures 'work' must go to Sohail who never ceased to use his initiative when problems arose, which as can be imagined was fairly frequently.

It should be pointed out that in most of the tests outlined below absolute figures were not sought. The main idea behind the tests was simply to compare devices, that is to say for example that device $A$ heats the test room better than device $B$. The test room was not intended to resemble a room in the target area, but simply intended as a pure Laboratory designed to perform comparative tests regarding smoke and heat.

Smoke and heat test sheets are marked with a room number which varies from 1 to 3. Room No, 1 was the original test room in Kacha Gari, but unfortunately it was found to be too exposed to the outside environment and hence it was felt that experiments conducted in this room were more dependant on the weatlier outside than the device being tested inside.

As a result of this Room No. 2 was constructed with double entrance doors and three internal walls thus giving much less exposure to wind and greater thermal inertia i.e, the stove being tested had the main effect on the air being monitored in the room. This was easily the most tightly sealed room and therefore gave the largest room temperature changes, although adequate air supply was subsequently identified as a shortcoming and it is suggested that the room be modified before testing is recommenced.

With the advent of the Gulf Crisis the testing had to be moved to University Town where the most suitable room was identified and established (loosely sealed and a chimney installed). This is called Room No. 3.

3.1 Smoke Testing. As detailed in chapter 2 above, the most important design criteria was felt to be the reduction of smoke. GTz had performed extensive smoke analysis in the past as part of it's bakery program, but unfortunately at the time of testing the equipment was being repaired in Germany, and so an alternative was required. The method developed involved drilling as many small holes as possible into the bottom of a round tin cup which is the same size as the filter papers used in the earlier mentioned machine. This cup is then attached to the suction side of a small lair dryer, and a small sample of the testing room air is drawn through the filter paper whilst the stove is being tested. Obviously all other factors such as test time, fuel used, room size \& ventilation, and chimney orientation, size \& cleanliness must be kept constant if a proper stove comparison is to be performed.

At first the filter papers were weighed before and after the test, but the results proved difficult to obtain and were found to be inconsistent with the visual outcome. All filter papers are given in the appendices. 
Furthermore, the devices without sliding doors were all tested with the combustion chamber door open, which is in accordance with the target population's identified practice.

3.2 Cost Estimation. A quick and easy method of estimating the cost of devices was necessary, so by using existing device's prices in the bazaars, their weight and the experience of GTZ's metal workers in Kacha Gari, it was found that in general metal heating stoves cost approximately 20 rupees per kilogram for the material and 16 rupees per hour for labor. Obviously this method was only valid at the time of it's development in March of 1991.

3.3 Cooking Ability. The ability of a device to cook food is proportional to it's power output and it's PIIU (Percentage of lleat Utilized). The PIIU may be very high, but if only a small fire can be constructed in the fire place, then the food will take a long time to cook. Conversely a large fire with a very low PllU will also give long cooking times. More to the point is the fact that PIIU varies with power rate. PIIU should not be quoted without mentioning the power rate at which the PIIU was obtained. Averages have been used in the past, but in this series of tests it was attempted to measure each device's pIIU for the device's whole range of power outputs, thus obtaining a PllU yersus Power curve for each device. It involved firing the device whist it is sitting on top of scales that are sensitive enough to measure the amount of fuel consumed in a three or four minute period. Unfortunately such sensitive scales were easily damaged under these conditions. Furthermore, the arrangement was extremely sensitive to weight movements which naturally happen quite frequently in a burning fire! The cooking time was measured with a watch and the PIIU was measured with various modified versions of the 'International Standard Water Boiling Test'.

3.4 lleating Ability. The ability of a device to heat a room is dependant on the size of fire that can be accommodated, the efficiency of the device in transferring the heat to the room, and the amount of smoke generated in the process which necessitates opening doors and windows or ceiling flaps. The method adopted by the research team to measure the comparative heating ability of each device was simply to measure the change in test room temperature the device effected in unit time.

3.5 Efficiency of Combustion. It is in this area that the project made the most progress principally due to the introduction of a "TestoTerin 33 Gas Analyzer' by Jurgen Usinger in January, 1991.

The process of combustion in simplified terms involves combining oxygen from the air with volatile gases and Carbon from the fuel. If combustion is not complete, which may be because there is too much excess air ( $\lambda$ ) cooling the process down, then the oxygen will only partly combine with the Carbon, thus producing a lot of Carbon Monoxide. In good combustion all the volatile gases and Carbon is transformed, thus producing a lot of Carbon Dioxide, and little Oxygen \& Carbon Monoxide.

Ideally a well designed heating stove will have a high combustion chamber temperature and a low flue gas temperature which implies that the heat of combustion has been extracted from the exhaust gases before it escapes up 
the chimney. Values of Exhaust Gas lleat Loss (qA) are also given, and these should ideally be as low as possible. Throughout the gas analysis tests the Carbon Monoxide levels were too high for the Testoterm 33 to measure, and too erratic to draw conclusions, and so unfortunately had to be ignored. For a more detailed discussion on the analysis of results the reader is referred to the report entitled "Research \& Design of Cooking and lleating Devices" (Ref 3 ). The reader should also bear in mind that this was the first time that such a device was attempted to be used, so the early results in particular may be somewhat spurious although in all cases where the gas analysis results were consistent, they were given far greater credence than any results obtained by other methods. The results obtained by the gas analyzer were also far more consistent than those obtained by previous methods.

Ideally the exhaust gases are measured whilst the device is on scales. This would then provide the researcher with combustion performance figures for the whole range of operating conditions. In fact it is really only through such a technique that a proper comparison of each device's combustion characteristics can be made. Unfortunately this method proved rather hazardous, particularly in the makeshift laboratory necessitated by the Gulf Crisis, and as a consequence only a handful of results could be obtained using this method. Furthermore, obtaining reasonably reliable results for one device would take a researcher experienced in this technique approximately two weeks's trouble free work. Every technique mentioned here was completely new to everybody concerned at the time the research was carried out. Regardless, the gas analyzer broke down after two month's operation, and had to be returned to Germany for repair.

Furthermore, it came to be known that the target population invariably use their devices with the combustion chamber door open lexcept at night when they close the device down). All laboratory tests were conducted under the same conditions, except where a sliding door was fitted or where indicated otherwise. It was also assumed that a grate door, where it existed, would be kept closed, and this practice was also observed during testing.

3.6 Deformability \& Blockability. This is a measure of how quickly the device deforms and blocks. To ascertain this the device was fired continuously until $100 \mathrm{~kg}$ of appropriate grade wood has been consumed. Notes are taken regarding how often the device needs to be cleaned, how long it takes to burn $100 \mathrm{~kg}$ of wood and how deformed the device is at the end. This gives the tester a rough idea of whether the device will block in the field and how long the device is going to be serviceable for. 


\section{Field Testing}

Field testing of improved devices is usually a difficult task. When the testing is required to be performed amongst a strict Muslim society that does not allow their women to be seen by other men, the task becomes more difficult. When this fact is combined with the fact that the ideal time to test is winter and that the target area is a cold mountainous area then the difficulties involved become horrendous. Credit for performing this arduous task must go to Mr. Wajid Syed and the support staff at KIDP who on more than one occasion Ioaded food and 'improved' devices on to donkeys and trudged many kilometers through deep snow to continue delivering and monitoring the progress of the devices being field tested.

\subsection{Ilousehold Selection Criteria}

Households to which stoves are distributed for the small scale field test were selected according to the following criteria (200ct90):

1. Genuine interest in an improved system

- household where people feel the need of saving fuel

- household ready to invest in a new type of stove

2. Feasibility of monitoring

- household accessible in winter

- cooperative household (KIDP local staff, hh visited by LDC, Lady FAs..)

3. Possible multiplication effect

- household in different locations of KIDP's project area

- household where women usually gather

4. The household should have a minimum of 8 members above 10 years of age.

5. The source of income for the family should be from agriculture.

6. The family should be using metal stoves previously.

7. The wood should be collected by the family members.

\subsection{Field Testing Methodology}

The primary purpose of the field tests were to determine the acceptability of the new devices in terms of fuel consumption, smoke and useability.

The change in Fuel Consumption was determined by performing 24 hr fuel consumption tests on the households before and after the improved devices were introduced. This technique is felt to be the only reliable method of definitely ascertaining a positive or negative affect on a household's fuel consumption.

Smoke output was determined by Drager Carbon Monoxide Tubes. It was assumed that the Carbon Monoxide levels present in the rooms is proportional to the amount of smoke the devices emit. Smoke levels were also observed, Regardless, it is desirable to reduce Carbon Monoxide levels to acceptable international standards. The Acceptability of the new devices was ascertained via a questionnaire, the details of which are given in the appendix. 


\section{The Devices}

Similar devices have similar names. If only a slight change is made in the design of a device, then the name is incremented by one i.e. from A1 to A2. If a more significant change is made in the design of a device, then the letter is incremented by one i,e. from A1 to B1 etc.

Table 5: A comparison of selected results from the device's laboratory tests sorted on power and name order. The figures given are averages from multiple results obtained during approximately one hour testing sęssions, the complete details of which are given in the appendix. An asterisk ( ) indicates that the results given are averages of the average results presented in the appendix.

\begin{tabular}{|c|c|c|c|c|c|c|c|c|c|c|}
\hline Name & $\begin{array}{l}\text { Cost } \\
\text { Rs } \\
\end{array}$ & $\begin{array}{l}\text { Pow } \\
\mathrm{K}_{w}\end{array}$ & PIIU & $\begin{array}{l}\text { Chim } \\
\text { Temp }\end{array}$ & $\mathrm{O}_{2}$ & $\mathrm{qA}$ & $\lambda$ & $\mathrm{CO}_{2}$ & $\begin{array}{l}\text { Room } \\
\text { No }\end{array}$ & $\begin{array}{l}\text { T'emp } \\
\text { Diff }\end{array}$ \\
\hline Beller A3 & 160 & 9 & 13 & 348 & 14 & 44 & 3.8 & 5.7 & 3 & 15 \\
\hline Beller A1 & 160 & 19 & 11 & 490 & 11 & 36 & 2.1 & 9.9 & 3 & 14 \\
\hline Beller A3 & 160 & 25 & 7 & 602 & 7 & 34 & 1.6 & 12.9 & 3 & 17 \\
\hline Beller D ${ }^{\dagger}$ & 160 & 11 & 17 & 450 & 8 & 27 & 1.8 & 12.0 & 3 & 10 \\
\hline Beller D2 & 160 & 16 & 13 & 562 & 7 & 30 & 1.5 & 13.6 & 3 & 14 \\
\hline Jurgen $B 2^{*}$ & 300 & 10 & 17 & 370 & 12 & 35 & 2.7 & 8.0 & 3 & 10 \\
\hline Jurgen B1 & 300 & 12 & 19 & 401 & 12 & 33 & 2.3 & 8.8 & 3 & 9 \\
\hline Zaher $\mathrm{A}^{*}$ & 250 & 8 & 14 & 292 & & & & & & \\
\hline Zaher B1 & 370 & 5 & 10 & 208 & 17 & 44 & 5.8 & 3.5 & & \\
\hline Zaher B1 & 370 & 9 & 17 & 381 & 12 & 34 & 2.6 & 6.8 & 3 & 5 \\
\hline Zaher B1 & 370 & 15 & 17 & 351 & 11 & 27 & 2.2 & 10.0 & 3 & 10 \\
\hline Zaher B2 & 370 & 10 & 19 & 313 & 17 & 77 & 4.3 & 4.3 & 3 & 9 \\
\hline Zaher B2 & 370 & 11 & 18 & 284 & 15 & 48 & 2.7 & 5.9 & 3 & 10 \\
\hline Zubada A2 & 380 & 15 & 4 & 517 & 10 & 37 & 2.0 & 10.8 & 3 & 13 \\
\hline
\end{tabular}




\subsection{The Bellers}

\section{1 .1 Bellers A1,2 \& 3}

The Beller A1 was identified in the study performed in May of 1990 as being by far the most popular device currently in use by the target population. It is extremely cheap (160 Rs), it can accommodate large logs in it's combustion chamber which is very important in winter and is convenient from a regular user's point of view because then it is less likely to require frequent tending, and it has special two centimeter high tawa supporting lugs around the primary combustion chamber which enable a large fire to be built under the tawa when nan is being baked.

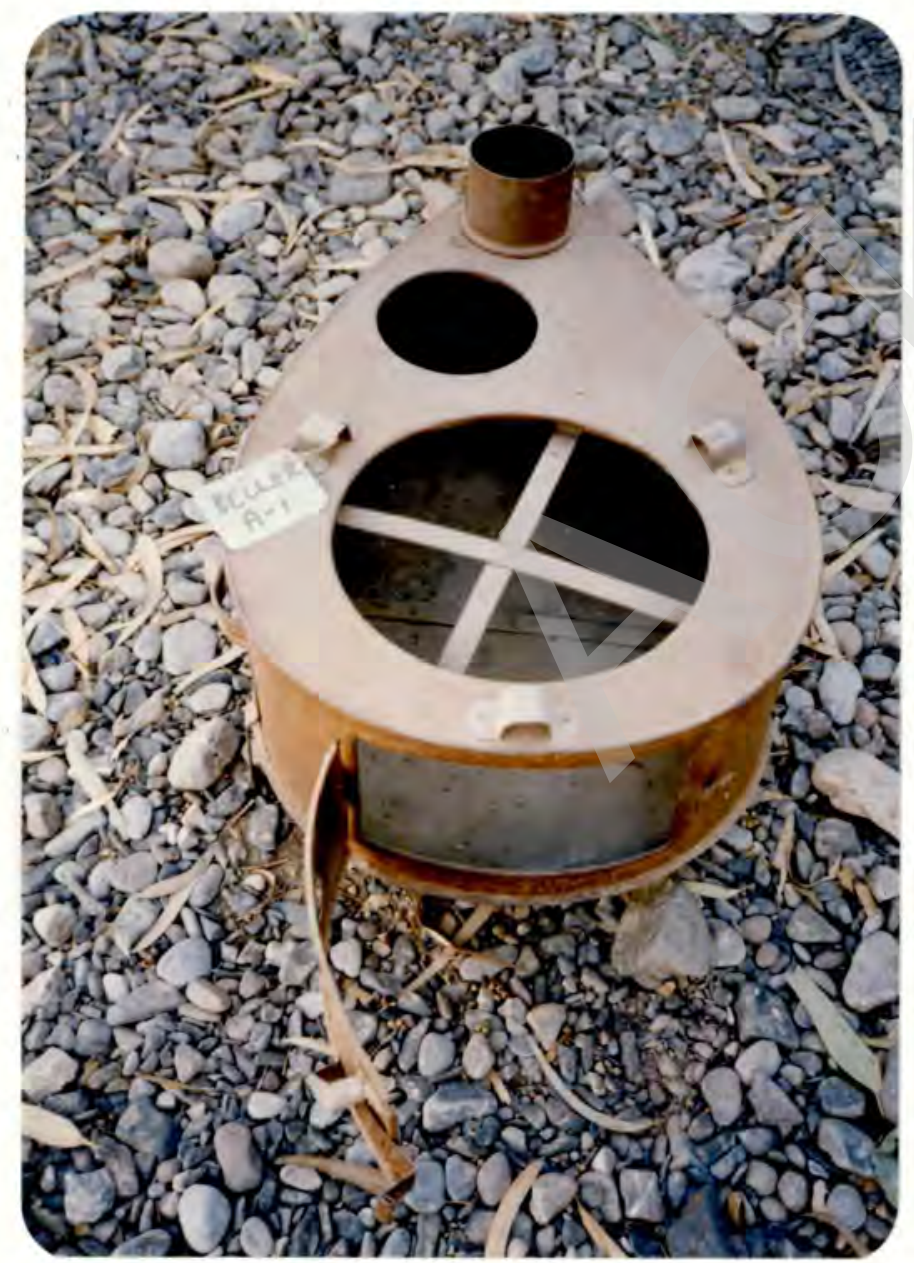

Fig 5.1.1: The Beller A1
The most serious drawback identified in this stove was it's smoke output, although in hindsight it becomes apparent that maybe the test procedure was unfair because possibly the people never sit the cooking pot on top of the tawa lugs as was done when the device was being smoke tested in Kacha Gari and University Town. Needless to say smoke tests performed on this device were never completed due to the testing room became uninhabitable which is evidenced by the filter papers shown in the appendix of Beller A1 test numbers 1,2 \& 13. According to $\mathrm{Mr}$. Mohammed Ali, a school teacher from Kalam, the Bellers only smoke when wet wood is being used, when it is windy, during cooking, and if the chimney is blocked (Ref 6). The current practice is to clean the body every two or three days, and the chimney with burning kerosene twice a month.

Twelve tests with an average power rate of $14 \mathrm{~kW}$ gave an average PIIU of $13 \%$ which is reasonable, and an average maximum chimney temperature of $525^{\circ} \mathrm{C}$ which is quite high (tests $9 \& 10$ excluded). The overall results were quite erratic though and may be questionable. Test no. 13 performed on this device (shown in table 5) gave quite acceptable results i.e. low average chimney temperature, $\mathrm{O}_{2}, \quad \mathrm{qA} \& \lambda$ and high $\mathrm{CO}_{2} \&$ Room Temperature Change.

In an attempt to improve the performance of the Beller A1, various size baffles were introduced into the combustion 
chamber. These new devices were called the Beller A2 \& A3. The baffle appeared to have little effect on the A2's Chimney Temp $\left({ }^{\sim} 556^{\circ} \mathrm{C}\right)$ and PIIU, and only managed to improve the performance of the A3 slightly in so far as the chimney temperature dropped to $348^{\circ} \mathrm{C}$ at $9 \mathrm{kw}$.

The Beller $A 1 \& A 3$ data in table 5 has been prepared in ascending power order to demonstrate to the reader the typical effect increasing a fire size has on the combustion process. As can be seen from the table, as the power (fire size) increases from 9 to 25 kilowatts:

- the PIIU declines from 13\% to $7 \%$ (less percentage of the available heat goes into the cooking pot)

the chimney temperature increases from $348^{\circ} \mathrm{C}$ to $602^{\circ} \mathrm{C}$ (1arger fire)

the exhaust oxygen concentration decreases from $14 \%$ to $7 \%$ (more oxygen combines with the fuell

less potential heat energy is lost up the chimney (qA decreases from $44 \%$ to $34 \%$ ) possibly because combustion is more complete at the higher combustion chamber temperatures

the excess air ratio decreases from 3.8 to 1.6 (much more of the available air is being used in combustion and not simply carrying the hot exhaust gases up the chimney)

Carbon Dioxide output increases from $5.7 \%$ to $17.9 \%$ (more Carbon is completely combining with Oxygen from the air thus producing more $\mathrm{CO}_{2}$ and less Carbon Monoxide)

\subsubsection{The Beller c1}

The Beller C1 is a much larger version of the Beller A series. It's most noticeable feature is a water tank over the second pot hole. The four test results on this device made available to the author at the time of writing indicated an average PIIU of $10 \%$ at an average power rate of $14 \mathrm{~kW}$. Furthermore, the PIIU decreases as the power rate increases which lends further credence to the test results. The most astounding feature of the test results is an average maximum chimney temperature of just $113^{\circ} \mathrm{C}$, which is very good, although no gas analysis was performed, so it is not known whether the result is a consequence of incomplete combustion, large excess air or actual heat transfer. llowever considering that the exhaust gases had to pass a large water tank before being measured, the later cause, which is the most desirable, is the most likely. The further development of this device was discontinued due to it's cost and indication of non desirability of an incorporated water tank by KIDP, but the lessons learnt regarding the large heat absorption ability of water were invaluable.

\subsubsection{Laboratory Testing the Beller D1,2 \& 3}

The ' $D$ ' series of Bellers, while still being labelled Deller, were the first. serious attempt at breaking away from the Beller mold, and under the circumstances could have easily been called the Martina.

The internal and external geometry is slightly different to the Beller A series, a baffle has been incorporated, but more importantly, a grate and collection box 
has been added, the overall result of which has been (see table 5):

- decreased exhaust gas Oxygen concentration

- decreased lost potential heat energy (qA)

- decreased excess air $(\boldsymbol{\lambda})$

- increased chimney temperature

- increased exhaust gas Carbon Dioxide concentration

which all indicate greatly improved fuel combustion, and result in a significantly improved PIIU. Whilst it is not desirable to have a high chimney temperature, the increase shown here also indicates improved combustion and greater potential heat energy being made available to the stove designer for the same amount of fuel input. In hindsight this device displayed the best combustion performance of all the devices (lowest $\mathrm{O}_{2}, \mathrm{qA} \& \lambda$ and highest $\mathrm{CO}_{2}$ ), but unfortunately nothing has been done to utilize the increased heat energy made available. As a result the stove did not heat up the test room significantly more than it's predecessor (see the far right side column of table 5).

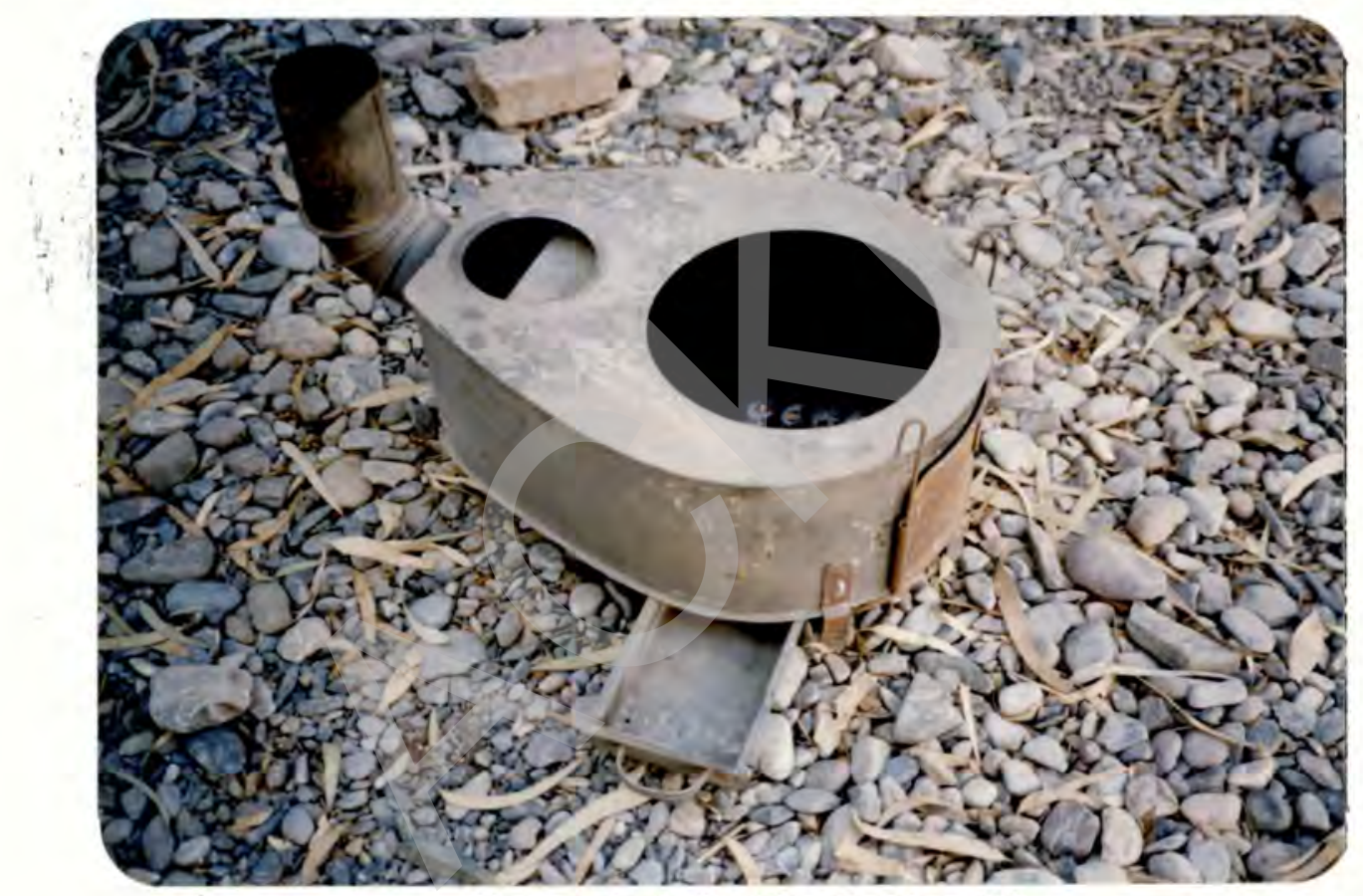

Figure 5.1.3: The Beller D3

The difference between the D2 \& D3 is a sliding front door which was designed to decrease the amount of smoke and excess air. The innovation appeared to be successful in the area of smoke reduction (see filter papers D3-1 \& D3-2), but that result is inconsistent with the excess air ratio results which did not appear to change.

The third test on the Beller D3 was one of the few performed where the device was tested on scales accurate enough to measure the change in overall weight within a four minute period whilst a fire is burning inside. During each four minute period the exhaust gas is analyzed and the PIIU estimated. Such a test procedure enables the tester to obtain the performance of a heating device over a range of 
fire sizes in a much shorter time than is possible by other means. This method also enabled consistency checks to be performed whilst the laboratory test was proceeding. Once patterns had emerged, inconsistent results were discarded, and the test repeated immediately. The end result is a reasonably smooth consistent set of points which permit easy curve fitting and extrapolation, as can be seen in the graph of the results (figure 5.1.4). Unfortunately, whilst most of the measurements taken were consistent, the chimney temperatures obtained were inconsistent with those obtained in tests $1 \& 2$ where $14 \& 12$ readings were taken respectively, and so cannot be easily ignored. For the purposes of attempting to present an accurate picture, both results have been included in figure 5.1.4. The 'average' chimney temperature results obtained from tests 1 \& 2 are shown with a '(1)' \& '(2)' beside the points marked ' $C$ ', and a curve has been drawn incorporating these points. The curve incorporating only the points from test 4 have been fitted with a dashed line. Obviously such results need further investigation.

Now for the first time the reader has a graphic image of the effect increasing the fire size has on the performance of a device. Furthermore, a graphic image of the performance of this device in absolute terms is also available to the tester for subsequent comparison against other devices.

Complete combustion does not start occurring in this stove until the power rate reaches $40 \mathrm{~kW}$ which is the point at which the excess air ratio reaches one, the Oxygen concentration reaches a low $5 \%$, and the Carbon Dioxide concentration reaches $19 \%$ which is close to the maximum possible under the Earth's present atmospheric conditions of $21 \%$ i.e. the concentration of $\mathrm{CO}_{2}$ currently in the air (at sea level).

At the operating conditions necessary to adequately heat a room in Kalam i.e. 15 $\mathrm{kW}$, the excess air ratio has increased to 1.5 , the Oxygen concentration has increased to $7 \%$, and the Carbon Dioxide concentration has decreased to $15 \%$. Below this power rate the curves are seen to rise and fall more steeply,

While this stove appears to have superior combustion performance to the A series of Bellers, and any other stove developed by FECT so far, it is still a long way from optimal, but quite acceptable under such tight cost constraint conditions.

\subsubsection{Field Testing the Beller D2}

A Beller D2 was sold to Mr Mohammed Shah, who is a driver with KIDP. Ile complained that the device smoked very badly and had taken it upon himself to remove both the baffle and the chimney flap, thus making it very similar to the Beller A1, except for the grate and ash box. lle was subsequently chosen to test a Jurgen B3.

A second Beller D2 (?) (and chimney water heater) was sold to a Mr. Iqbal llussain who is a neighbor of the KIDP employee Sham Sherhan. llis model featured a baffle, a punched hole grate and a sliding drawer ash box, which he emptied every second day. It had been set solidly in mud in a typical Kalami kitchen which comprised an ante room for livestock, and a small trap door in the roof for light and ventilation. lle said the new device halved his wood consumption and gave of very little smoke. Ile complained that it was impossible to place small pots on the large pot hole, and that the stove and entrance door heights should be increased 
from 20 to $30 \mathrm{~cm}$ to accommodate logs of Oak instead of the Pine they are forced to use now because that is the only wood they can cut into small enough pieces to fit in the door (ref 8).

A third Beller D2 (?) (as well as a double chimney water tank) was sold to $\mathrm{Mr}$. Mehboob Khan who lives in a village just north of Kalam. "The household was satisfied with the device. They said it was better in wood consumption and smoke production. The flap has been taken out since the house lady did not know how to use it and also they felt that wood was available in abundance, They were satisfied with the heating and cooking ability" (Ref 5). "The water heater was a very big advantage as it helps them to keep everything clean" (Ref 6).

\subsubsection{Field Testing of the Beller D3}

Five Beller D3s were commissioned to be produced by a metal worker in Khwas Khela for $350 \mathrm{Rs}$ each. On inspection it was found that cheap material had been used, and that the construction technique was not very good, however the copies of the Beller D3 were much better than the copies of the Zaher A3, possibly due to the Beller being much closer to what they're accustomed to producing.

A Beller D3 was sold to Maulana Shah Jehan who lives near Kalam. "lle said that the device emits smoke because of the baffle, as it restricts the flow of smoke through the chimney. Ile also said that it consumes more wood as the wood has to be cut in to small pieces and hence burns very quickly, just like leaves. For this purpose the door has to be enlarged. Ile said that the heating and cooking ability of the device was better than the previous device. On inspection the device was in very good condition, without any major deformations" (ref 5).

A second Beller D3 was sold to a man named Maulana Rahim, who is a teacher in Miandam, and a colleague of Zarem Basher, for 150Rs (?). Previously his wife had been using an open fire so it was understandable when he complimented the device on it's smoke reduction ability. Ile also said that the new device gave of more heat, but consumed the same amount of wood. Ile complained that a small pot holder had not been provided to him, and that the chimney kept blocking at its right angle bend two meters above the stove. Furthermore, he was aware of the existence of hot water tanks, and was extremely keen to be sold one. 


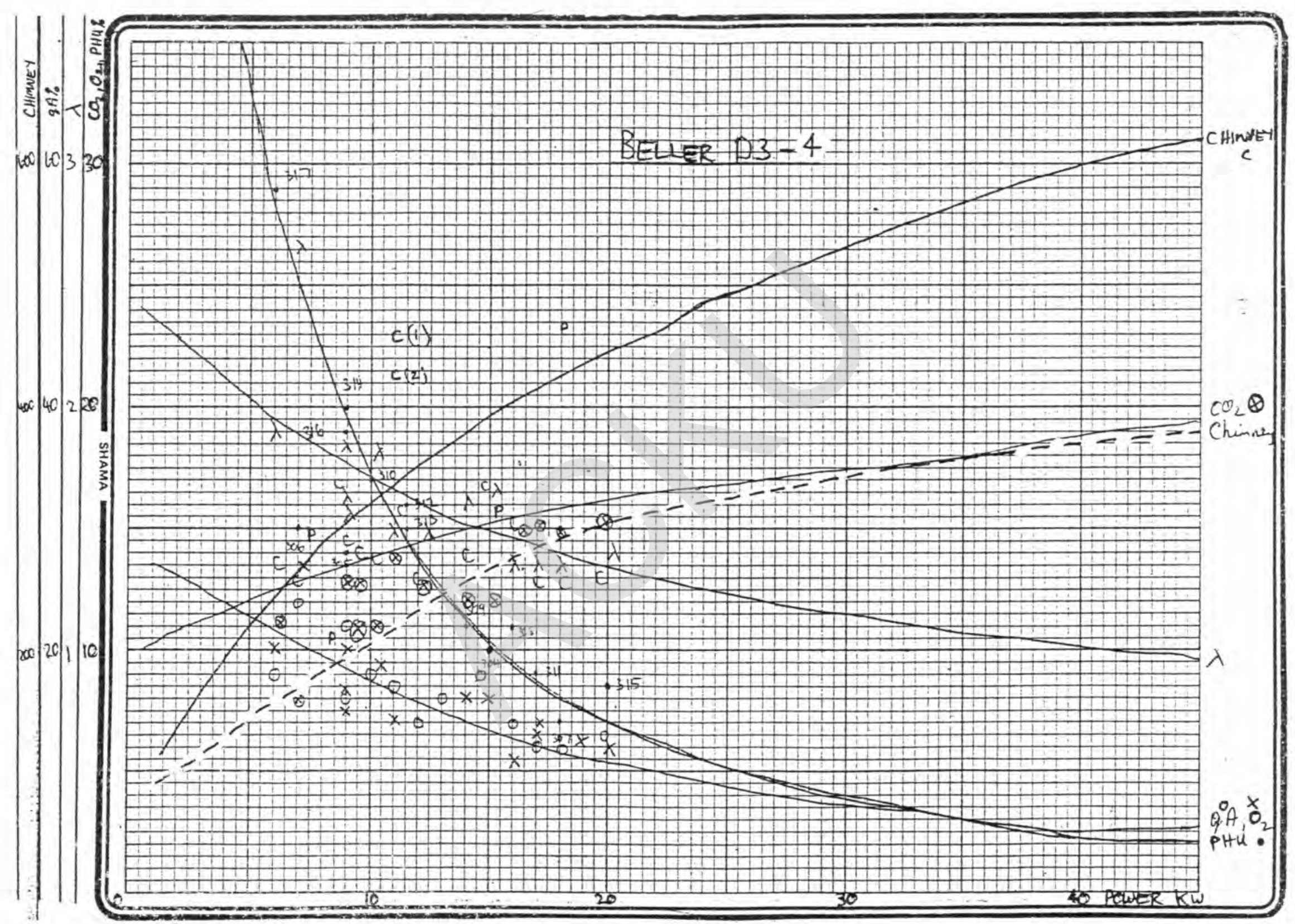

Figure 5.1.4: A graph of exhaust gas analysis data versus power for the Beller D3 (test no. 4). 


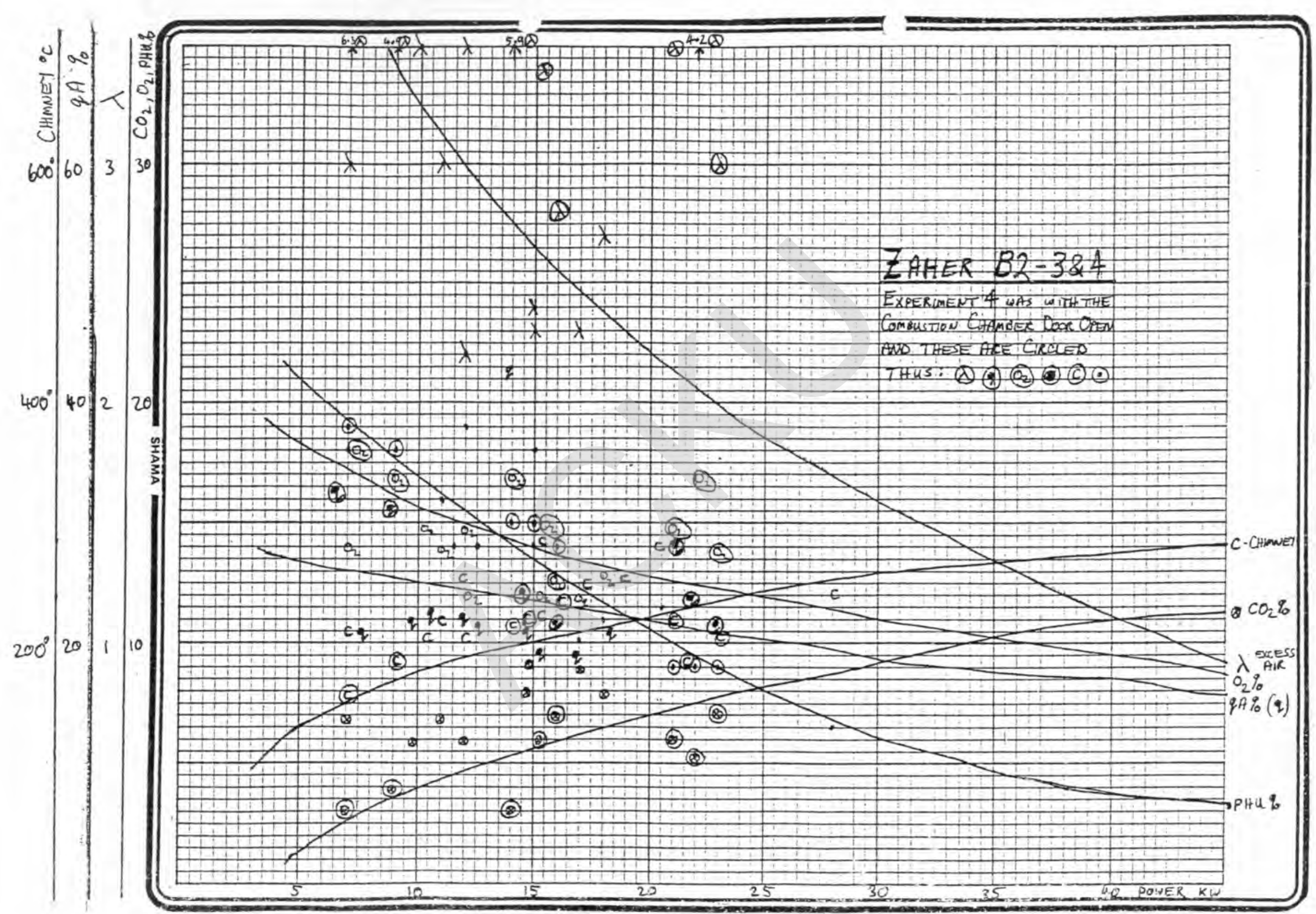

Figure 5.1.5:

A graph of exhaust gas analysis data versus power for the Zaher B2 (test nos. $3 \& 4$ ). 


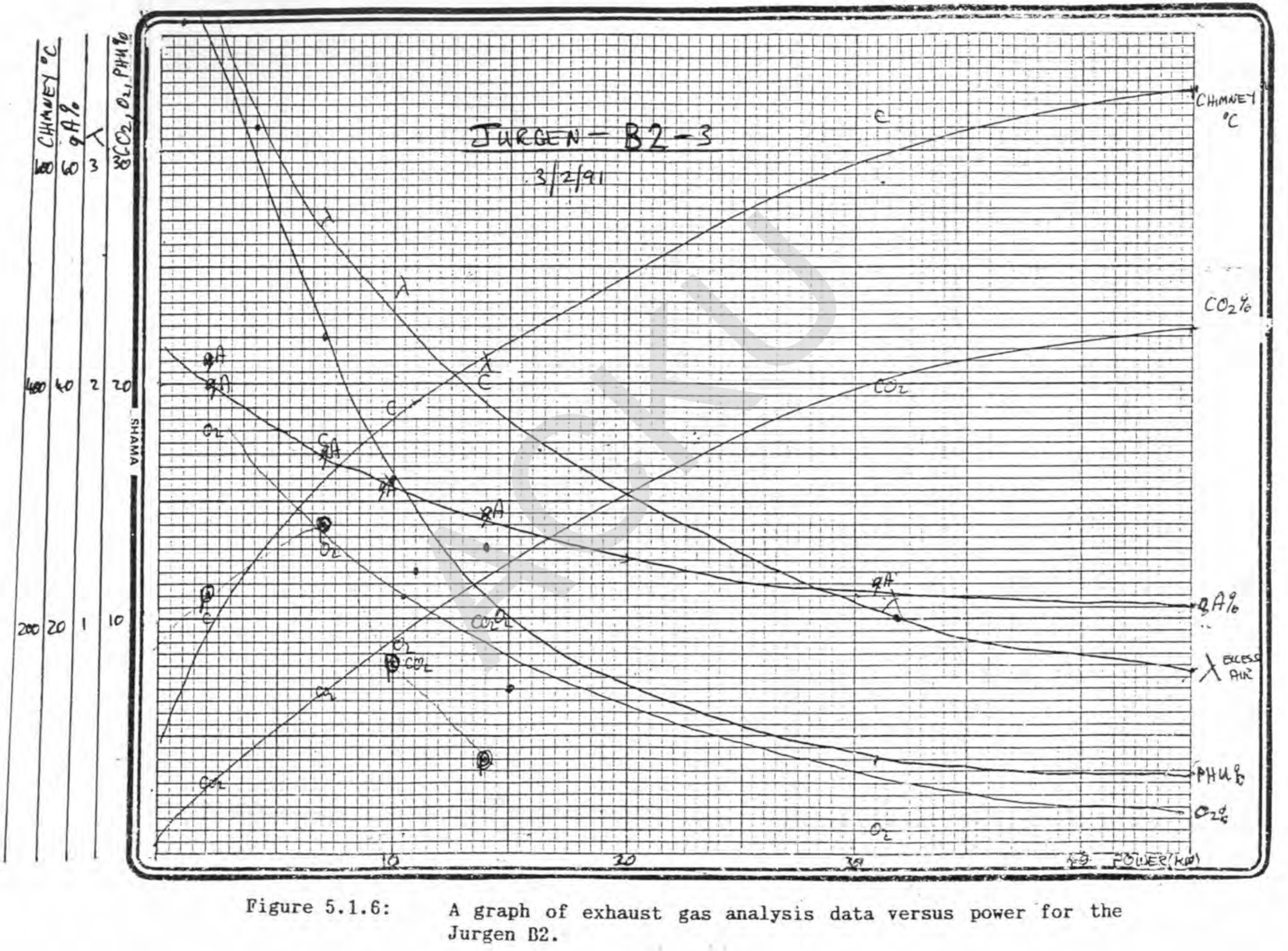




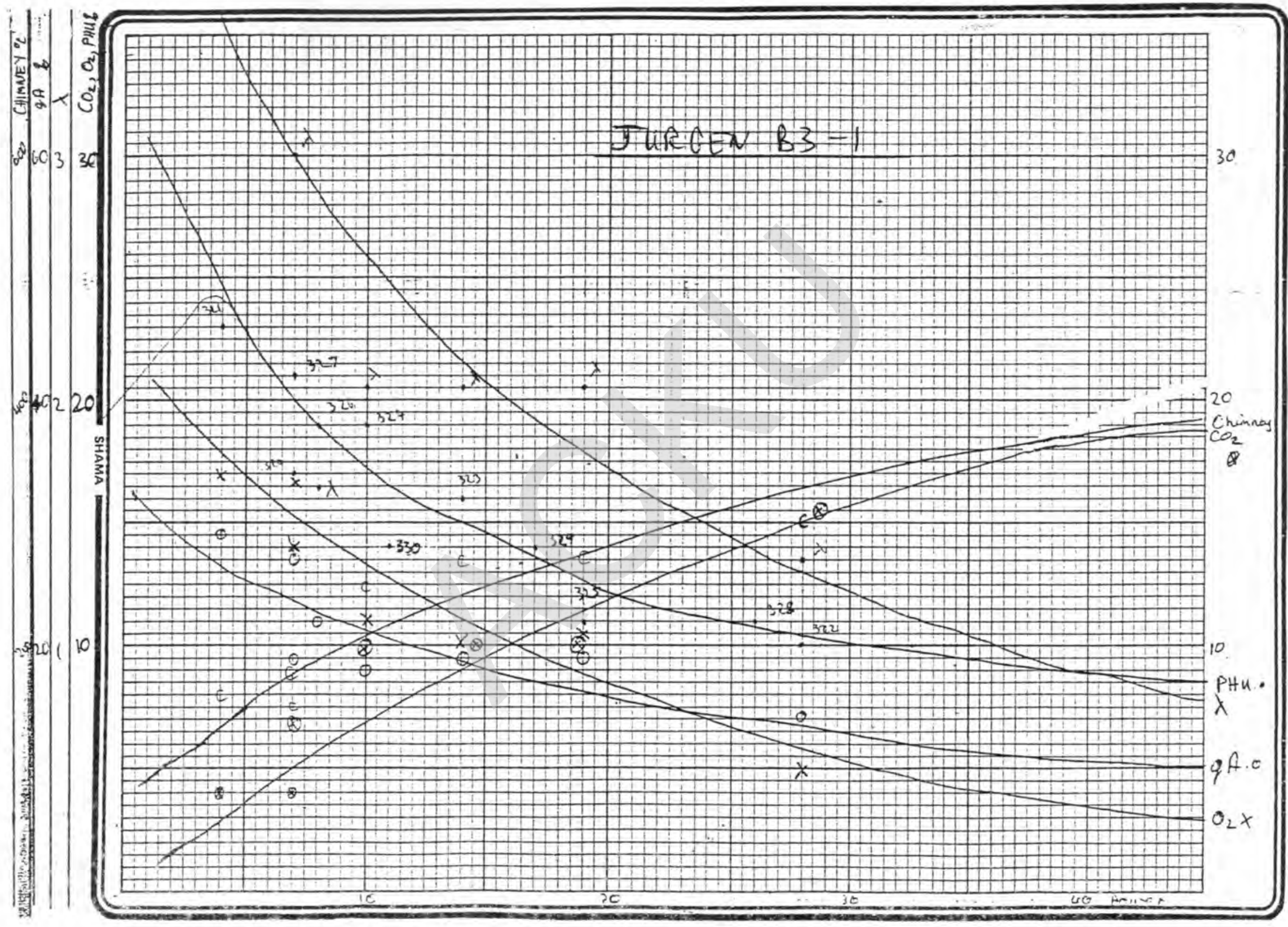

Figure 5.1.7:

A graph of exhaust gas analysis data versus power for the Jurgen B3. 


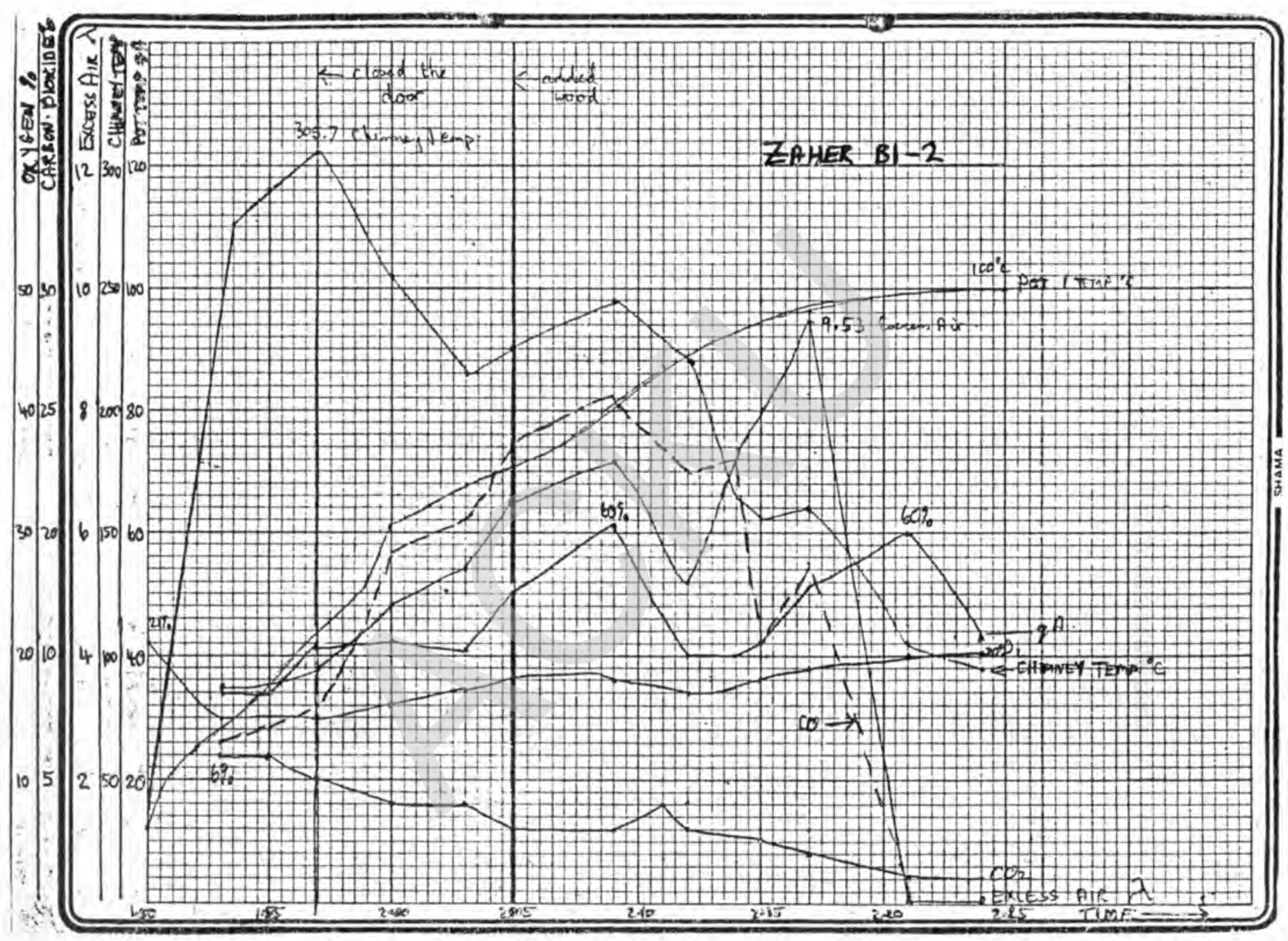

Figure 5.2.3: A graph of exhaust gas analysis data versus time for the Zaher 131 (test no. 2). 


\subsection{The Zahers}

This style of device, originally intended to burn wood, diesel or saw dust, was designed by Eng. Zaher of the Afghan Project in August of 1990 . It is radically different in design from what the target population are accustomed to, and much reservation was expressed regarding it's acceptability from a purely aesthetic point of view. The design features a drum shaped combustion chamber with grate, and a narrow 'bridge' at the top, with an incorporated heating box, leading to a chimney on the far side. The A1 model, which wasn't necessarily the first, included a water tank, and was quickly abandoned for reasons of cost and disapproval by KIDP. The A2 to A5 incorporated various slight geometrical and design changes. The B1 \& B2 designs were conceived by Jurgen Usinger who considered the general concept promising enough to try and improve on it.

\subsubsection{Laboratory Testing of the Zaher A2}

The $\mathrm{Z}$ aher $\mathrm{A} 2$ was tested four times in Kacha Gari and found to give an average PIU of $14 \%$ at $8 \mathrm{~kW}$ which is comparable to the A series Bellers, but below the D series Bellers and the Jurgens (see table 5). The most noticeable laboratory feature of this device was it's average maximum chimney temperature of $292^{\circ} \mathrm{C}$ (excluding test no. 3) which is in the range normally reserved for devices fitted with water tanks and costing considerably more than 300 Rupees. The room heating ability of this device was comparable to the other devices, although the test results are from room number 1 , whereas most of the other results are from rooms $2 \& 3$, so the results should not really be compared. Unfortunately no exhaust gas analysis was performed on this device. When comparing this device with the other devices the reader must bear in mind that this device has by far the smallest combustion chamber and is thus more likely to effect significant fuel savings in the field. A second noticeable quality of this device was it's low smoke output as is evidenced by smoke filter papers $A 2-1$ \& $A 2-2$. This device continued to perform excellently in this area throughout the whole test series.

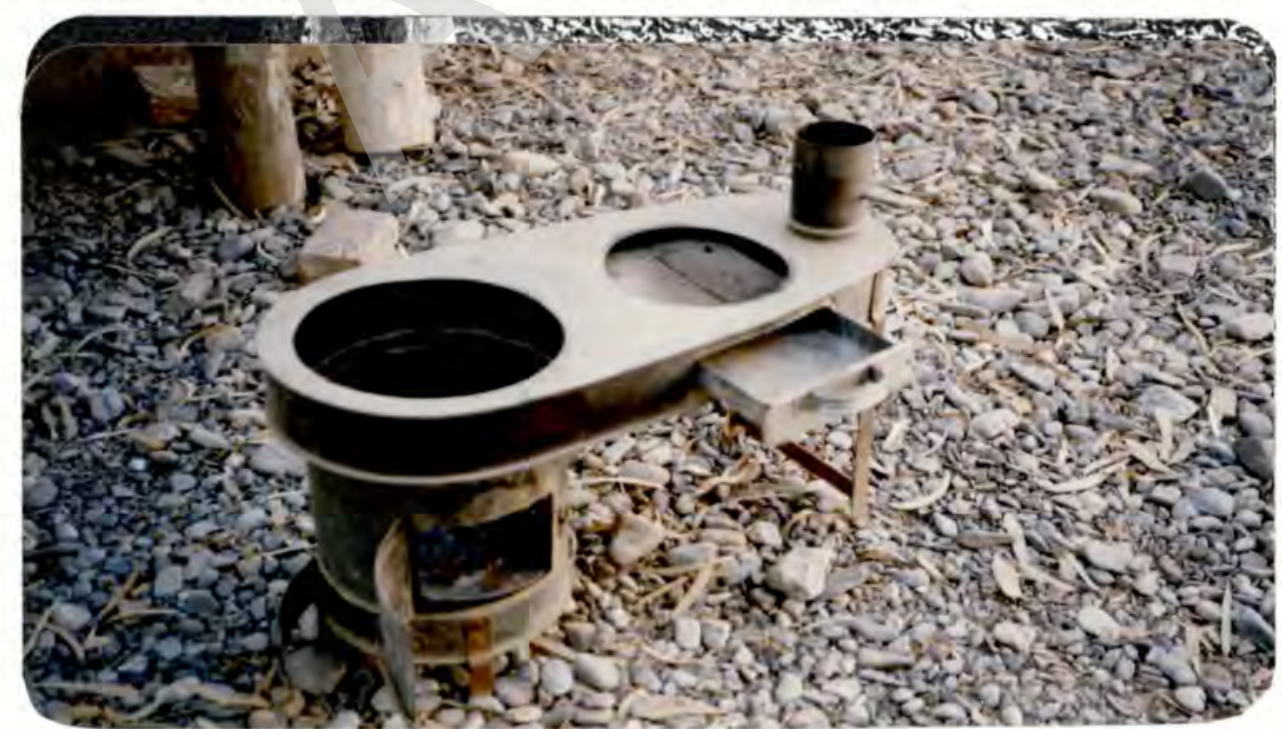

Figure 5.2.1: The Zaher A2 with baking drawer pulled out. 


\subsubsection{Field Testing of the Zaher A3}

Five Zaher A3s (very slightly different to the Zaher A2) were commissioned to be produced by a metal workshop in Khwasa Khela for 350 Rs each. Ile was provided with one model to copy from. On inspection of the completed articles it was found that cheap material had been used, and that the construction technique was very poor. The Zaher A3 is possibly a difficult device for the Swat Valley metal workers to copy because it is unlike anything they have ever made before. The copies of the Beller D3 however were much better.

The most prominent and famous field tester of DESP stoves is a secondary school teacher named Sareem Basher who lives in Miandam. Ile is always willing to try new ideas, and invariably gives extensive feedback, and so it was only natural that a highly experimental stove such as the Zaher $A 3$ should be field tested in his house. Most of his feedback was good i.e. faster cooking, much less smoke and more room heat for no increase in his family's wood consumption. Unfortunately it smoked the kitchen heavily until Mr. Basher removed an elbow from the chimney. Furthermore, the area between the baking box and the outer skin blocked very quickly and was sufficiently difficult to clean to warrant its complete removal by a metal worker in his local bazaar. The remaining hole was then sealed with the removed material (Tanveer, the Technical Director of the FECT project, had warned the research staff of similar tar blocking experiences whilst field testing the Chari B1 in Montserat). The baking compartment was not very effective anyway as the heat was concentrated on the combustion chamber side thus burning the food there, and leaving it raw on the chimney side, although he felt the baking tray to be very useful and recommended it's improvement. The baffle was also very loose (no-one used the baffle in the Chari B1 in Montserat!), and a request was made for a hot water container.

A second Zaher A3 was field tested by a priest in a rest house near Kalam. llis model featured a removable grate, a feeding door in the side, an ash door in the front and no flame concentrator. lle was extremely dissatisfied with it. lle complained that the baking tray was useless and unnecessary, and that it blocked very quickly and then smoked very badly. Upon inspection by the field staff it was found that the baffle was locked closed, but the priest was no longer open to discussion. Ilis device was immediately exchanged for a Beller D1.

A third Zaher A3 was sold to Mr. llabib Khan. After five days of use he gave it the following extensive analysis (see Ref 7 ):

\section{Positive:}

1. Water and food is boiling/cooking faster than on the old Beller. It appears that the drum shaped combustion chamber directs the fire to the pot, and the narrow part keeps the fire from escaping directly through the chimney.

2. The stove is also good for making chappatti or rotei on a 'tabakhei',

3. The stove outputs more heat. People are sitting further away now.

4. It seems to need less firewood than the old one, and even less with the door closed, although short pieces of wood are a problem.

5. So far the stove has been quite good with regard to smoke. There is less smoke when the door is closed.

6. Until now there is very little soot deposited in the narrow part, so it seems there will be no blockage problems, and cleaning will not be difficult or 
required too frequently,

7. This stove is significantly different from the Beller. Bricks were used in the past for a baffle, but the grate is a new idea.

8. At 250 Rs it was not considered expensive by friends and neighbors. Mr, Ilabib Khan was even prepared to pay for one out of cast iron, just so long as he got a good stove.

\section{Negative:}

1. The combustion chamber and door are too small for our big pieces of wood. 2. Feeding wood 'up' into the combustion chamber is difficult, therefore reduce the height of the legs.

3 . The chimney flap, whilst being very good for regulating the air flow, was hard to move ever since we purchased it. With soot it may become totally stuck.

4. Ashes are not falling down through the grate, thus requiring frequent cleaning.

5. The upper sheet and grill curves when the stove is hot, so stronger material should be used.

6. After I realized the usefulness of the baking compartment, I found it to be too small.

7. The thermal inertia and usefulness of the stove could be improved by placing bricks or water in the open space beneath the bridge, thus producing a kind of 'Kachelhofen' effect.

\subsubsection{The Zaher B1}

As stated previously, Jurgen Usinger found the Zaher A2 design sufficiently promising to attempt improving on it. As field tests had amply demonstrated, the 'bridge' region of the stove was a problem area regarding blocking with tar and soot. To overcome this problem Jurgen made the whole baking box able to slide out by mounting it on rods and incorporated scraping edges on the top and bottom thus making the narrow gap area cleanable by pulling the box out and reinserting it. Naturally this raised the cost considerably, and furthermore such a mechanism would obviously require a certain amount of training for each customer. It is worth mentioning at this stage that some people found it difficult to understand the water tank removal mechanism in the Chari $\mathrm{B} 1$ whilst it was being field tested in Montserat, so the effectiveness of the 'bridge cleaning' mechanism from a user point of view was somewhat dubious.

A second significant change introduced by Jurgen was to make the combustion chamber considerably larger and to remove the grate. Because exhaust gas analysis was not performed on the Zaher A2, unfortunately it is not know the exact effect these design changes had on the combustion process.

The Zaher B1 was one of the most extensively laboratory tested devices, as can be seen by the results given in appendix 2. Also for the first time the laboratory results were graphed on a time basis (The earlier graph shown of the Beller D3-3 had 'power' on the absisca) and these are shown in figure 5.2.3. Such graphs are very good for revealing extraneous results, particularly in the area of chimney temperatures and exhaust gas analysis.

From the test results given in the appendix, one can see that the PIIU still averages a very good $15 \%$ at $8 \mathrm{~kW}$, but most noticeable is the exceedingly low average maximum chimney temperature of $238^{\circ} \mathrm{C}$, which is even lower than Zaher $A 2$. 
Combustion in this device was obviously not as complete as that which occurred in the Beller D3. The $\mathrm{O}_{2}, \mathrm{qA}$ and $\boldsymbol{\lambda}$ levels were generally higher, and the $\mathrm{CO}_{2}$ levels were generally lower. This fact goes some way towards explaining the low chimney temperature and the accompanying apparently low room heating ability of this device. Furthermore, the section of the bridge nearest the combustion chamber began to deform so seriously as the tests proceeded that eventually the device had to be abandoned as the smoke output became too severe (Filter Zaher B $1-5 \& 9$ )

\subsubsection{The Zaher B2}

As a result of the difficulties experienced with the Zaher B1, and drawing on experience from other designs, the Zaher B2 was conceived, and it featured a reinforced bridge area, and a sliding door. Unfortunately it did not live up to expectations. Whilst the reasonable PIIU performance was retained, the chimney temperature \& $\mathrm{CO}_{2}$ output were lower, and the $\mathrm{O}_{2}$, qA \& $\lambda$ values were considerably higher, which all implies even worse combustion than in the Zaher B1. Gas analysis and PIIU estimation on laboratory scales resulted in figure 5.1.5.

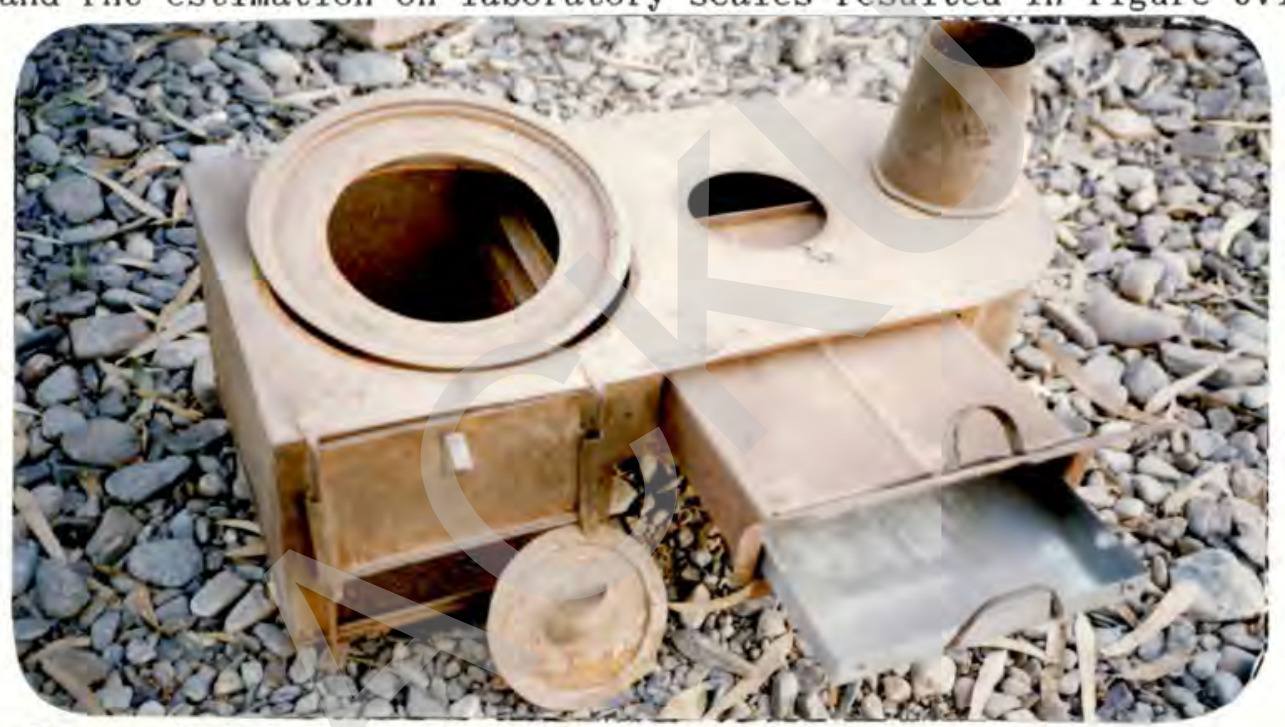

Figure 5.2.3: The Zaher B2 with baking drawer pulled out.

Inspection of figure 5.1 .5 shows that the excess air ratio does not reach one until well after $40 \mathrm{kw}$, and even at this point the oxygen level is still very high $(9 \%)$ and the Carbon Dioxide level very low (11\%). The percentage of heat going up the chimney (qA) is comparatively high for the whole range of operating conditions. The PIIU curve appears to lie in between the low values of the Beller D3 and the high values of the Jurgen B3.

Inspection of figure 5.1.5 is also interesting because experiment 4 was conducted with the combustion chamber door open, and these are shown circled. Whilst interpretation of these results is far from conclusive, it is possible to observe some definite trends which agree with what one would expect. If the combustion chamber door is left open the excess air ratio, 0xygen and exhaust gas heat loss (qA) rise, whilst the Carbon Dioxide, PIU and chimney temperature fall. These are obviously undesirable effects on the combustion process and further imply the need for an automatic combustion chamber door closing mechanism, such as a sliding or top hinged door. This device was not field tested. 


\subsection{The Jurgens}

This series of stoves were conceived by none other than Jurgen Usinger himself, and were by far the most laboratory and field tested devices. The design introduced many new features which were subsequently adopted by other stove designers. The general concept is to, by means of a complicated inner baffle design, force the hot exhaust gases to go up close to the first (and only!) pot, and for them then to travel down a narrow $(\sim 5 \mathrm{~cm})$ channel on the other side of the baffle, which is adjacent to the outer skin of the device. The sooty species of pine in use by the target population necessitated a relatively wide flue channel to avoid blocking. The exhaust gases then leave via a chimney opening which is tapered so as to facilitate the flow of exhaust gases, and to also make attachment of different sized chimneys in the households easier.

It has no grate, a 'sunken' lid design, and a well supported and reinforced pot hole to help reduce the smoke output. The external shape is much more similar to the target population's traditional Beller shape than the Zaher for example, so it has a greater chance of initial acceptance. Further added features include a sliding door at the front which is designed to reduce the excess air ratio and smoke output, and an angled side hinged door in the back which makes cleaning the chimney much easier.

The operation of this device should be 'foolproof', as the only moving part is the sliding door at the front. A problem area could be price, as at an estimated cost of 300 Rupees it is nearly double what the average target population consumer is currently paying. Using thinner gauge metal would reduce the cost, but also the lifetime. A marketable compromise should be reached in this regard.

The Jurgen A1 was a design that became confused in it's transferral for construction at Kacha Gari. It deformed severely in the $100 \mathrm{~kg}$ wood test, and was abandoned after only a further five laboratory tests.

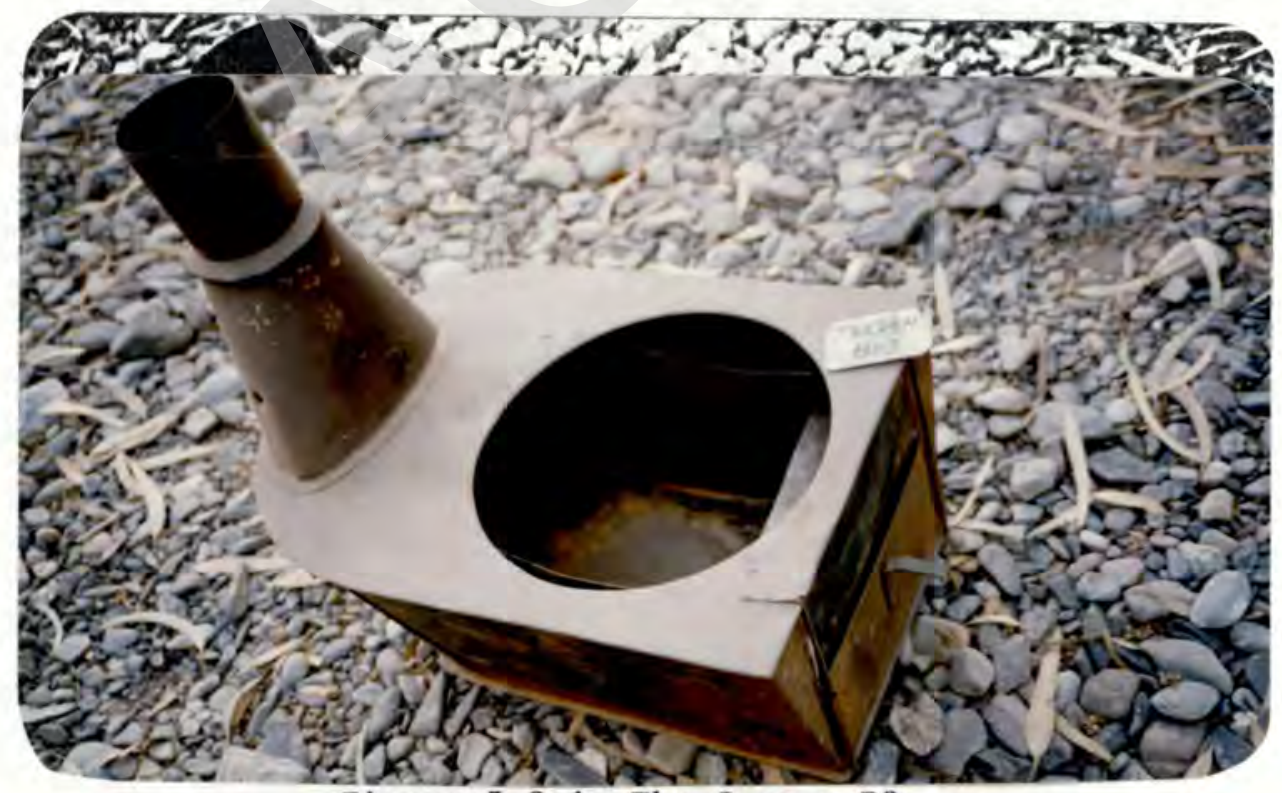

Figure 5.3.1: The Jurgen B2 


\subsubsection{Laboratory Testing the Jurgen $\mathrm{B} 1,2 \& 3$}

The Jurgen B1 much more closely resembled the designer's original concept. It is rectangular in shape with slanting sides, a tapered rear, a $28 \mathrm{~cm}$ pot hole, and measures $22 \mathrm{~cm}$ in height, $37 \mathrm{~cm}$ in width and $50 \mathrm{~cm}$ in length. After passing the $100 \mathrm{~kg}$ wood deformation and blocking test, it displayed PIIU figures as good as the Zahers (18\% at $11 \mathrm{~kW})$ with combustion figures better than every other device except the Beller D3. It's chimney temperatures were generally lower than any other device (average of $329^{\circ} \mathrm{C}$ at $12 \mathrm{kw}$ ) except the Zahers, possibly due to better combustion occurring in the Jurgen than the Zaher, and it's room heating ability was generally higher than any other device tested. It's smoke output was consistently low, and remained that way for the whole laboratory test period.

The Jurgen B2 incorporated a different internal baffle design, and a slightly different (more complicated) external design. llowever, the laboratory results varied insignificantly.

An incredible change occurred in the performance of the Jurgen when the internal baffle was lengthened and bent over thus creating the Jurgen B3 (see figure 5.3.1 $\& 2$ ). Comparison of figures $5.1 .6 \& 7$ shows, at dubiously extrapolated power rates of $45 \mathrm{kw}$, a slight decrease in the combustion performance of the JB3 i.e. higher $\mathrm{O}_{2}(2$ to $3 \%)$, higher $\boldsymbol{\lambda}(0.8$ to 0.9$)$ and lower $\mathrm{CO}_{2}(22 \%$ !! to $19 \%)$, but an incredible difference in the heat transfer properties. The chimney temperature has dropped from $650^{\circ} \mathrm{C}$ to $400^{\circ} \mathrm{C}$, the qA rating from $22 \%$ to $10 \%$ and the PIIU has increased from $4 \%$ to $9 \%$. The change in performance is quite remarkable considering the small change in baffle design! It is important for stove designers to appreciate what a difference such small design change can make to the performance of a stove. An added effect of such a design change is to improve the structural rigidity of the device i.e. it is also much less likely to deform.

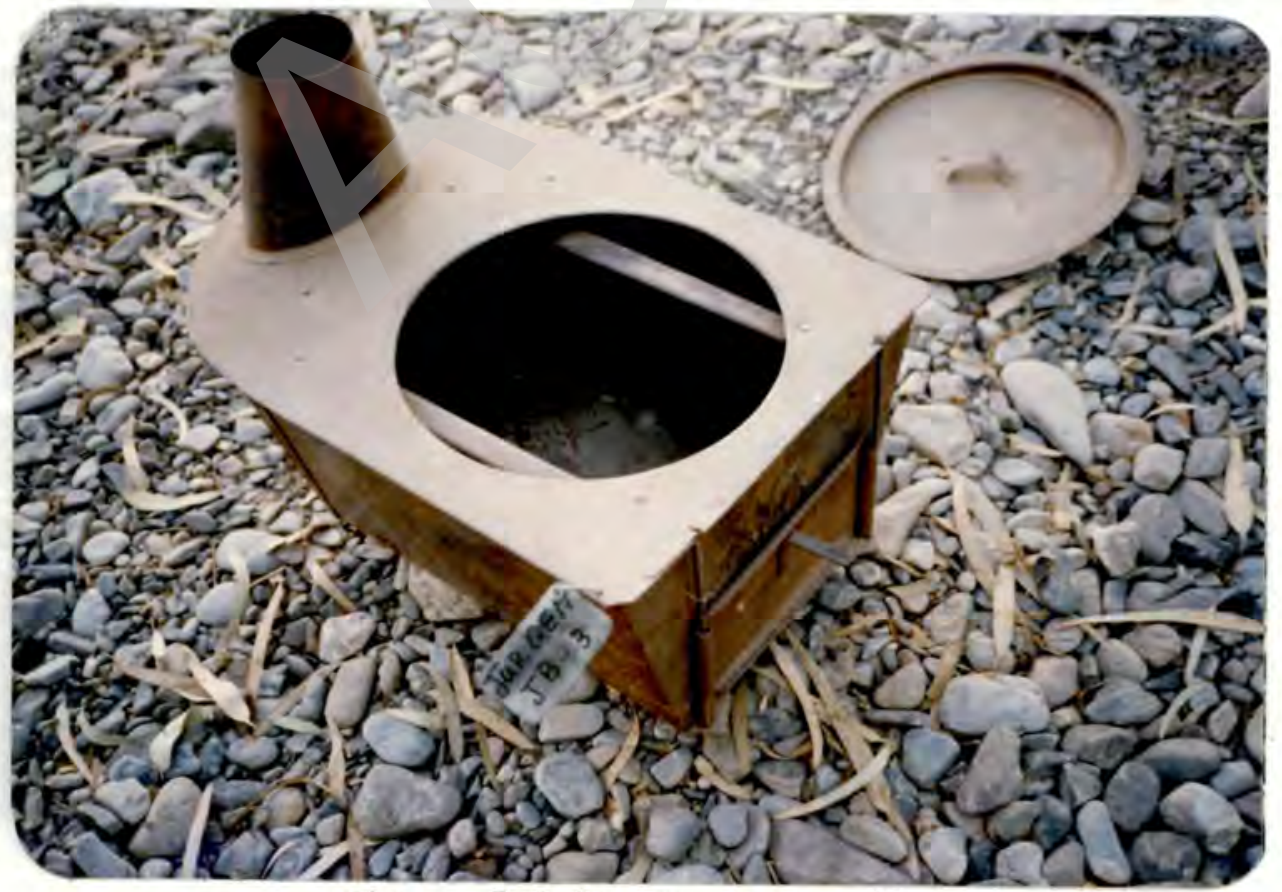

Figure 5.3.2: The Jurgen B3 


\subsubsection{Field Testing the Jurgen B3}

TThe following section draws heavily on the report entitled "Phase II of the Field Test" by kajid Syed - keference 8 ).

The most thorough field testing was that done on the Jurgen B3, possibly due to the heavy influence of Jurgen himself. Une severe drawback of this design could be it's reproducibilty, particularly of the inner baf'fle, by bazaar metal workers. An attempt at solving this has been sought through the production of templates (chablon). The success or otherwise of this solution is yet to be gauged. Chablons and five devices were manulactured by the kacha Gari metal workers at the University Town offices of GTZ-FECT (due to the Gulf Crisis) although slight modifications were present in each due to the continuous input of the designer, Jurgen. These were then shipped to Kalam by Wajid Syed who then, acting on the advice of Iqbal llussain of KIDP, distributed the new devices to Mr Amir Khan (1), Wazir Mohammed (2), Nazrat Mohammed (3), Mohammed Shah (4) and Zabib Ullah (5). "It appears that the selection criteria not adhered to due to the apparent close involvement of the selected households with KIDP (some were even employees). All the tests were carried out with the traditional Beller A1 type devices first, and then with the Jurgen B3s introduced by FECT, except for Mr Molianimed Shah who bad a Beller D2 which he had modified sufficiently to resemble a Beller $A 1$. The results were as follows:

Wood Consumption: The average $24 \mathrm{hrs}$ fuel consumption was found to be $35 \mathrm{~kg}$ which is almost the same as the result given in the "Assessment Study" of ' $34 \mathrm{~kg}$. The average household wood savings compared to the old device was $6 \mathrm{~kg}$, which represents a fuel savings of $17 \%$.

\begin{tabular}{||l|l|l|l|l|l||l||l||}
\hline House No. & 1 & 2 & 3 & 4 & 5 & $\begin{array}{l}\text { Total } \\
\text { Kg }\end{array}$ & $\begin{array}{l}\text { Average } \\
\text { Kg }\end{array}$ \\
\hline \hline Old Kg & 46 & 37 & 43 & 46 & 36 & 207 & 35 \\
\hline New Kg & 33 & 39 & 30 & 40 & 34 & 176 & 29 \\
\hline \hline Difference & -13 & +2 & -13 & -6 & -2 & -31 & $-6 \quad(-17 \%)$ \\
\hline
\end{tabular}

Table 2: Comparison of 24 hour fuel consumption figures in five households before and after the Jurgen B3 was introduced.

In observing a $13 \mathrm{~kg}$ fuel saving in households $1 \& 3$, the reader should bear in mind that their 'spot' kitchen temperatures were also down by $6 \& 10^{\prime} \mathrm{C}$ respectively. Ilousehold 4 , who used $6 \mathrm{~kg}$ less wood was not very co-operative, and generally critical of the project. Household 5 used $2 \mathrm{~kg}$ less wood, but they had washed their clothes during the Jurgen B3 $24 \mathrm{hr}$ fuel consumption test period. llousehold 2, who consumed $2.5 \mathrm{~kg}$ more wood, had developed his own device which he claimed to be better than our device.

In subsequent monitoring 2 months later, household 2 complained that the fire was difficult to start, and household 4 complained that the combustion chamber was too small and that too much coal is accumalated. 
Cooking: Households $2,4 \& 5$ were satisfied with the cooking ability of the new device. It cooked the bread on the Tawa adequately without any pot supports. llousehold 4 said that a slow fire cooked the bread perfectly in the same time as before. Unfortunately her Tawa had a very rounded bottom which rested on the inner baffle thus causing the release of much smoke from the sides. llousehold 5 used a clay Tawa which he claimed was perfect for the job. llouseholds 1 \& 3 complained that the heat was concentrated thus burning the nan in the middle and leaving it raw on the outside. Ilousehold 3 repeated this claim at a subsequent monitoring two months later.

Everybody was satisfied with the single pot hole. The only cooking devices they use are tea pots ( 3 times/day), tawa ( 2 times/day) and a pot for spinach (once a day). Their staple diet is corn bread and spinach (samchal) which is boiled in a pot with ghee and salt. Cereals, especially Dal Chana, are a rarity, and potatoes are mainly grown to be sold.

llot water for washing and cleaning is currently prepared in a pot or a large ghee tin on the stove. This method was felt to be preferable to paying more for a stove attached water heater.

Room lleating: All households, except for no, 3, expressed satisfaction with the heating ability of the new device even though 'spot' measurements indicated an average decline in room temperature of $4^{\circ} \mathrm{C}$.

\begin{tabular}{|c|c|c|c|c|c|c|}
\hline llouse No. & 1 & 2 & 3 & 4 & 5 & Average ${ }^{\circ} \mathrm{C}$ \\
\hline Old Device ${ }^{\circ} \mathrm{C}$ & 21 & 20 & 25 & 16 & 18 & 20 \\
\hline New Device 'C & 14,15 & 25,18 & 15,15 & 10,13 & 16 & 16 \\
\hline Average Change ${ }^{\circ} \mathrm{C}$ & -6 & +2 & -10 & -4 & -2 & -4 \\
\hline
\end{tabular}

Table 1: Comparison of spot kitchen room temperatures in five households before and after the Jurgen B3 was introduced.

llousehold 3 complained that the new device was not warm enough for his cattle who live in an attached room in winter. Experiments conducted in household 2 , who had typically damaged plastic window panes and door curtains ( 4 \& 5 had glass window panes), produced a temperature range of 18 to $25^{\circ} \mathrm{C}$ for fires ranging from small to large. The people did not appear to avail of the opportunity the new less smoke producing device presented to them to close their doors and windows because of the continued desire for light.

Swoke: By far the most noticeable and appreciated improvement in the new device was the level of smoke and carbon monoxide. "Previously one could feel the smoke, even when all the means of ventilation were open" (Ref 8). Even though Mr. Zabib U1lah's old device was in very good condition, his kitchen (house 5) became unbearable after only 15 minutes of closed doors and windows. The new levels of smoke were negligible compared to the old, and the Carbon Monoxide levels showed an average reduction of $74 \%$ in the one hour tests! 


\begin{tabular}{||l||l|l|l|l|l||l||}
\hline \hline Ilouse No. & 1 & 2 & 3 & 4 & 5 & Average ppm \\
\hline \hline Old ppm & 1 & 10 & 10 & 10 & 15 & 9 \\
\hline New ppm & 0,0 & 0,0 & 0,0 & 1,1 & 0,0 & 0 \\
\hline
\end{tabular}

Table 3: 20 second Drager Carbon Monoxide kitchen measurement figures in five households before and after the Jurgen B3 was introduced.

\begin{tabular}{||l||l|l||l||}
\hline Ilouse No. & 1 & 2 & Average ppm \\
\hline \hline Old ppm & 160 & 50 & 105 \\
\hline New ppm & 40 & 13 & 27 \\
\hline \hline Change & -140 & -37 & $-78(-74 \%)$ \\
\hline
\end{tabular}

Table 4: One hour Drager Carbon Monoxide kitchen measurement figures in two households before and after the Jurgen B3 was introduced.

llousehold no. 4 was found to be very smokey, but this was due to the fact that the lid was not put on the stove after cooking. In household no. 3 the Beller was smoking out of the lid due to heat deformation, but this was remedied by rotating the lid to a better fitting position and marking it.

\section{General:}

- There was a general disinterest or lack of knowledge regarding chimney flaps. llowever household 2, who was the only one who didn't get one, requested it, and said he would place it as high as possible to keep the heat in the chimney, and to stop children playing with it.

- The chimney opening in the Beller was $10 \mathrm{~cm}$, while the chimney diameters in houses $2,3 \& 4$ were only $9.7 \mathrm{~cm}$ !

- Everybody complained that 300 Rs was too much to pay for such a device. Ilouses $2 \& 5$ said 250 Rs would be more reasonable.

- Ilouse 2 suggested arc welding which was now available in Kalam Bazaar. Ilouse 5 suggested thicker more durable material for the inner baffle where it gets hot, and thinner material for the outer skin to increase the heat transfer. 'Replaceable' spare parts were also recommended.

- Follow up monitoring 2 months later indicated continued success in the areas of fuel consumption and smoke reduction, although smoke was seen to be emitting from both 1 ids in household 3 , and to a lesser extent in households $4 \& 5$.

- After two months the door in household 2 did not slide easily and household 5's baffle was twisted outwards. Ilouseholds $2 \& 3$ observed that the top plate becomes red hot during operation, but still no severe deformations have occurred. 


\subsection{The Lexcens}

The only way to extract a lot of energy from hot exhaust gases is to channel them through a narrow gap, but such a gap is likely to get quickly blocked, as has been the experience of most project designs in the past. Furthermore, where such a design has been combined with a water tank, severe corrosion has resulted. In response to this a design was envisaged by the author whereby a large round aluminium pot is sunk into a well fitting stove body. Such a design provides many advantages:

1. A lot of heat is extracted and stored from the exhaust gases.

2. The narrow gap baffle zone between the pot and the stove body is easily cleaned by removing the pot. A severe drawback is the fact that the pot will get very dirty, and even though it doesn't need to be cleaned, the target population will probably feel compelled to do so.

3. llot water, or a baking oven is always available to the user. If hot water is placed in the pot then the thermal momentum is increased significantly. One possible difficulty arises if hot water is left to boil in the pot for a long time thus increasing the humidity in the kitchens of households with an already large incidence of Tuberculosis. If the increase in humidity can be kept to an acceptable level by keeping a lid on the pot, or making the pot so large as to disable vigorous boiling, then enormous gains can be found in assisting the transfer of heat energy to the room via raising the humidity only slightly as well as the temperature. This needs to be investigated further.

4. The improved device is extremely cheap. The only added expense is a bazaar model fitted aluminium pot which will never corrode (150Rs). The pot also has many other uses and is easily replaceable.

5. A large pot hole area is provided for baking with tawa, although much smoke is likely to be released if and when the user changes from the tawa to the aluminium pot. This also needs to be investigated further.

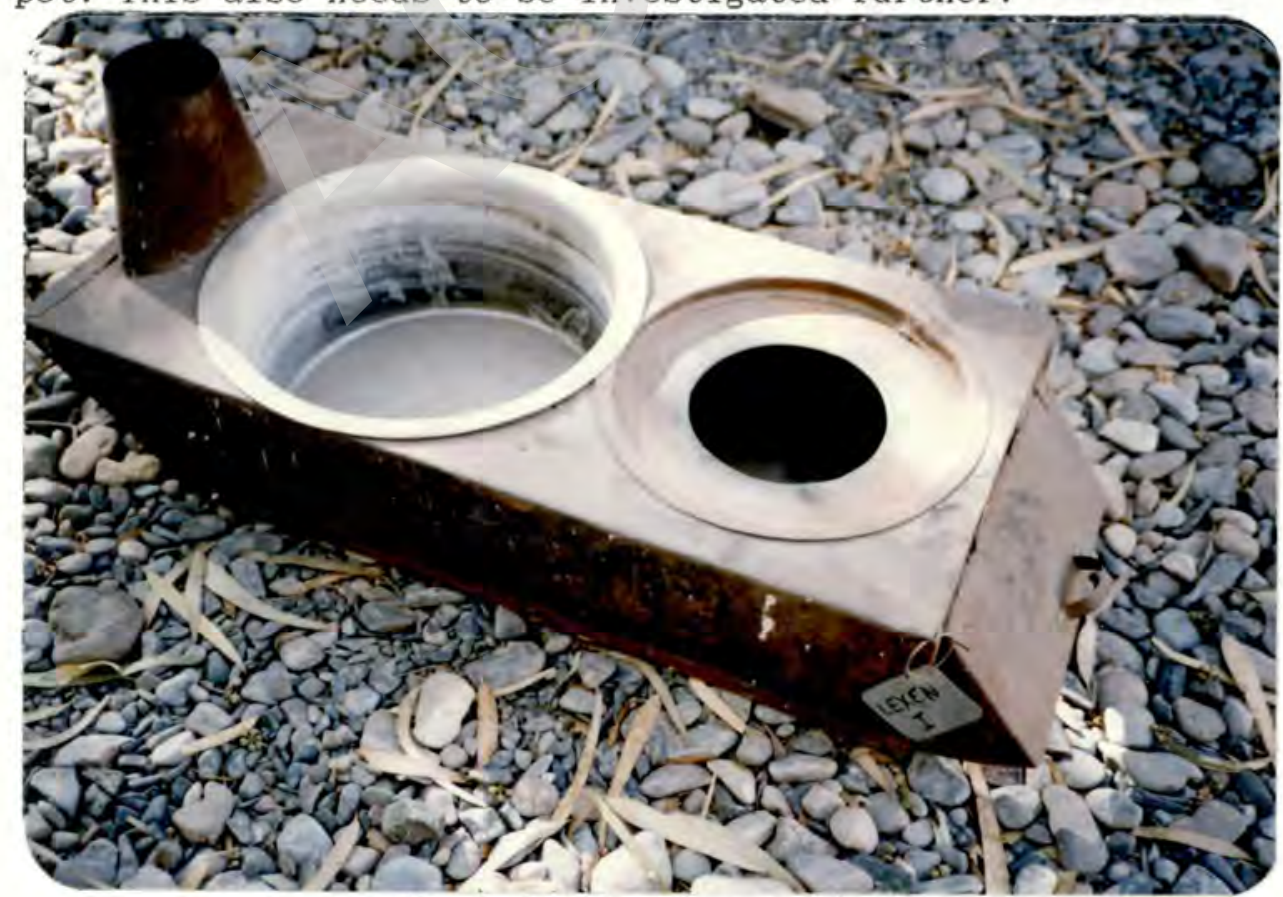

Fig 5.4: The Lexcen A1 
The design also featured a unique top hinged door with sides as an alternative automatic closing mechanism to the sliding door. Unfortunately, particularly in such a low stove, it made the fire extremely difficult to see and tend.

One model of such stove was constructed (Lexcen A1) and tested for durability by firing it with $100 \mathrm{~kg}$ of wood. No deformation was observed even though there was no water in the pot for half of the test period. A second improved model (Lexcen A2) has been designed but was not constructed due to the abandoning of the cooperation. The gap between the pot and the stove body is crucial and should be given due consideration when designing such a device and thoroughly tested in the laboratory before field testing begins. In such a design one centimeter can mean the difference between success and failure.

\subsection{The Baris}

This is a pure heating device intended for the Ilujra. It was originally designed by Eng. Bari Ayobi of the Afghan project. Fundamentally it is a drum shaped device with a heat absorbing empty metal cylinder inside and a chimney on the side so that a cooking pot could be heated on top (Bari A1). The idea is that hot exhaust gases are driven through a narrow cylinder thus being forced to give up their heat energy to the outer and inner walls. Crucial to this design is the gap between the inner drum and the outer wall. Design variations included having the chimney in the center (Bari A2), magnifying the dimensions (Bari A3 to A5), and substituting the empty cylinder with a water tank (Bari C1 \& C2) or metal rings (Bari B1).

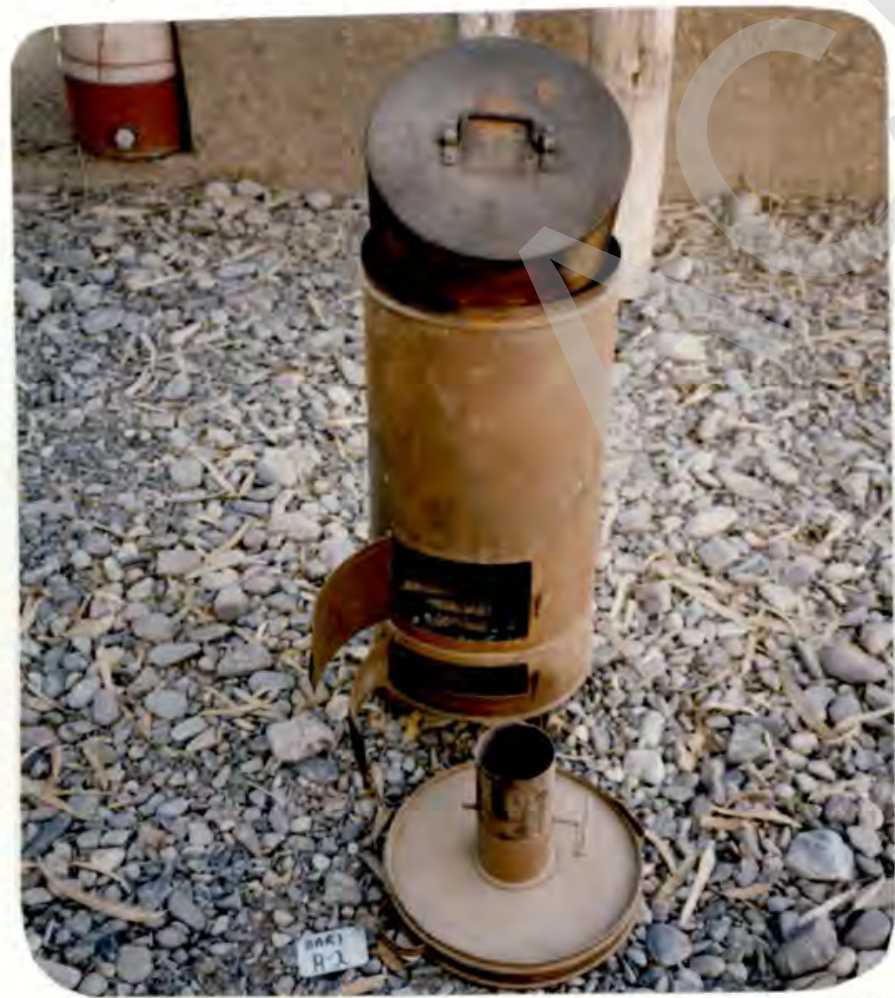

Figure 5.5: The Bari A2 with metal cylinder sitting on top.

\subsubsection{Bari Laboratory Tests}

Six laboratory tests were carried out on the Bari A2. The first five outdoor tests revealed the same average maximum chimney temperature as the Bari B1 i.e. $611^{\circ} \mathrm{C}$. The sixth test, which was the only one performed in the testing room, gave a chimney temperature of $200^{\circ} \mathrm{C}$ and a room temperature change of $11^{\circ} \mathrm{C}$, which is totally inconsistent with the first five tests. Every tester complained of much smoke, particularly when the baffle was closed, although filter paper Bari A2-6 does not show a bad overall smoke picture.

Six outdoor tests were performed on the Bari B1. At an average pcwer rate of $16 \mathrm{~kW}$ the PIIU was found to be $6 \%$ which is extremely low. Furthermore the average maximum chimney temperature was found to be $611^{\circ} \mathrm{C}$, which is very high. No smoke emptyproblems were reported, and this is substantiated by filter paper Bari B1-6. 


\subsubsection{Bari Field Tests}

Despite such poor test results found in Kacha Gari, three completely untested new designs were commissioned and sent to Kalam for field testing. Basically these were progressively larger magnifications of the Bari A1. The field test results were disastrous.

Taza Gul received the Bari A3 (the smallest one), and complained that it smoked from the lid and door more than his original device. Ile attempted to reduce the smoke emitting from the lid by sealing it with mud, but this was not very successful as the mud quickly dried and fell apart. The problem was eventually alleviated by removing the inner empty cylinder, thus making it very similar to the existing style of heating device found in the area.

Peter Kessler of KIDP received the Bari A4 (the middle size one) and despite experience in Switzerland with similar devices, could not stop it smoking very badly. After one attempted firing he removed it from his living room in disgust.

Sham Sherhan, an employee of KIDP, received the Bari A5 (the largest one), and found it performed reasonably well. lle would open the grate door to start it, and close both doors once the fire was going. Ile found it took half an hour to boil a pot of water, which confers with the laboratory result of $6 \%$ PIU given above. Ile cleaned the inner drum every second day and found it gave off little smoke. This is obviously due to the fact that because this was the biggest Bari, the area of the gap between the inner drum and the outer wall is sufficient to allow enough exhaust gas past and thus allow proper combustion of the fuel, which was definitely not the case with the Bari A3 \& 4. It was suggested to add a water heater, and also to change the design to accommodate large pieces of oak which are very difficult to cut, but burn for a very long time and emit relatively little smoke.

\subsection{The Double Chimney Water Tanks}

As the name suggests, this device is a double barrel chimney section with a galvanized water tank around it. This device was primarily designed as an addition to the Beller, but may be used on any stove with an exhaust pipe low enough to accommodate it. The first models were simple exhaust pipes passing through a water tank. Subsequent models incorporated a double inner tube design, which was meant to increase the surface contact area of the exhaust gases, and enable proper exhaust gas flow while the device was cold. Furthermore, the size of the water tank had to be increased considerably from 19 to 35 liters due to rapid boiling occurring in the smaller model after only 90 minutes. The 35 liter water tank heated the water to $77^{\circ} \mathrm{C}$ after three hours of firing. Chimney temperature drops of $200^{\circ} \mathrm{C}$ were recorded (Ref 4 ).

The first devices were found to block with tar and soot after a very short time, which is to be expected considering the narrow gap the exhaust gases have to travel through. Forcing the exhaust gases through a narrow gap is the only way to extract a lot of their heat energy, and so blocking from soot is seen as a necessary by product of efficient heating stoves. To overcome the blocking 
problem a metal ring with a long handle was inserted into the outer chamber. "One small hole on top leads the handles to the outside and gives the opportunity to clean the flue channels by moving the ring up and down without dismantling the chimney. The inner pipe can be cleaned as usual from the roof" (ref 4, page 19). Prices of these devices were estimated at about 200 Rs for the small model, going up to $350 \mathrm{Rs}$ for the larger designs, so their commercialization prospects as an 'additional' device are dubious.

\subsubsection{Pield Testing the Double Chimney Water Tanks}

Field testing of two of these devices was performed in Kalam. One such device with a 'medium' size water tank was 'sold' to Meboob Khan for about 200Rs, and during subsequent assessment he would not sell it back despite being offered 1000Rs and even though the internal cleaning ring and ashtray were both firmly stuck due to heat deformation. The compliments he and his wife gave the new device included better room heating, less smoke, faster cooking, less black dishes, and of course the constant availability of hot water for washing people, dishes, clothes, walls etc. etc... One improvement suggested by the women of the household was to make the opening to the water tank larger so as to enable snow to be easily put inside in winter. Furthermore, the tap was leaking after two months of operation, and it can only be repaired in Mingora.

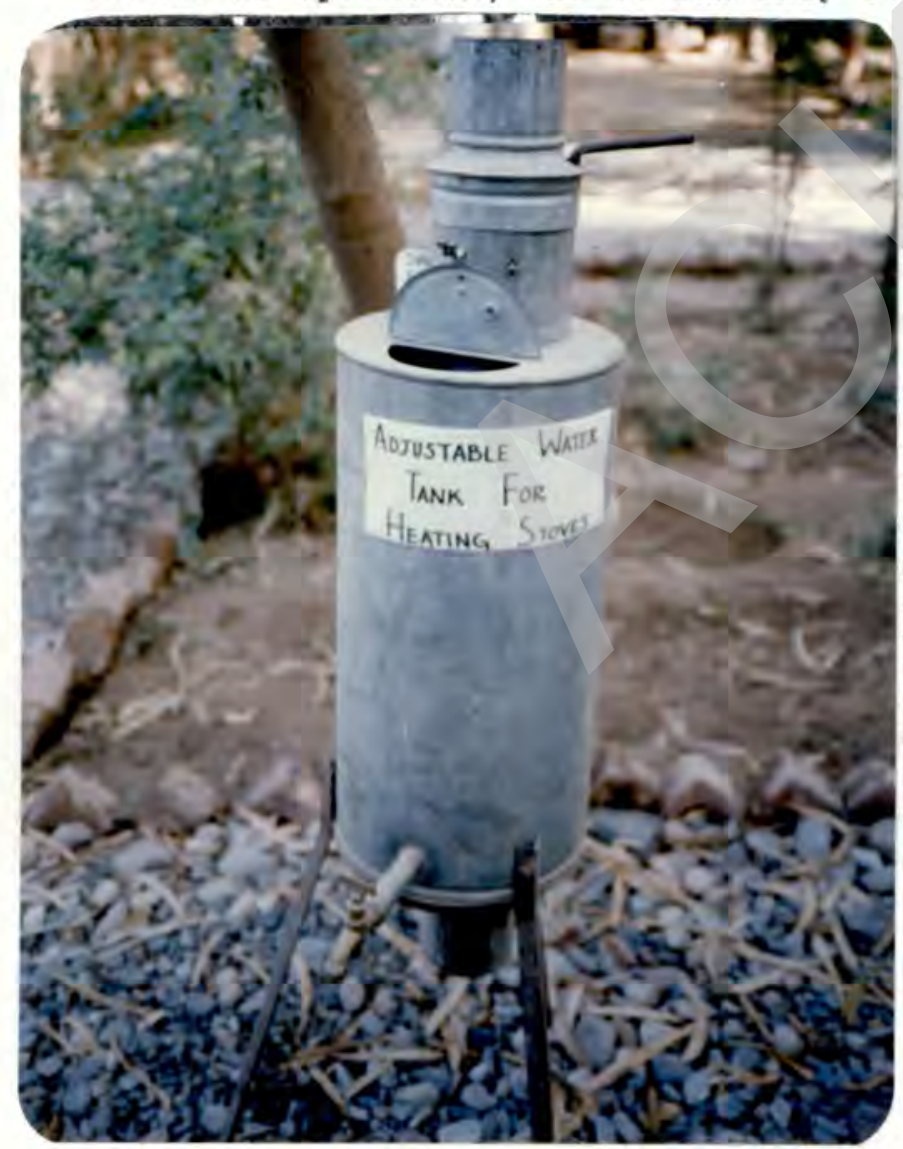

A second double chimney water tank with a much bigger triangular water tank $(45 \mathrm{~cm}$ high $x$ three $40 \mathrm{~cm}$ sides; $10 \& 12 \mathrm{~cm}$ diameter exhausts; Volume of 26 liters) told a very similar story except that the water heater was felt to be unnecessarily large.

Water and heat provide a particularly corrosive environment, and investigation into the long term durability of these device was not performed due to dissolution of the co-operation. The incredible desirability of hot water became apparent, and the possibility of incorporating it's availability into the design of a heating stove needs further investigation due to water's great ability to store heat energy.

Pigure 5.6: The Double Chimney Water Tank 


\section{Device Production}

Naturally following on from the area of device design, is the problem of device production. For the purposes of this discussion it is assumed that the metal workers who are currently producing heating stoves for the target population will be encouraged to simply change to the new device design. Following on from that assumption, it's all very nice to come up with a fantastic design that is liked by the target population and implementing bodies, but if it is not properly introduced to the 'right' producers at the 'right' time, and if it's not going to make the producers a profit, then the new device is not going to be made.

Fundamental to ascertaining device production is determining the supply and demand picture of cooking and heating devices in the Kalam region i.e. how many devices are being sold to the target population each year, where are those devices coming from, and what channels do they take to get to the target population.

The population of the target area is about one hundred thousand people (Ref 1 , 2.1). If we assume that the average household size is ten people, and that every household has a metal heating device which lasts a maximum of two winter seasons (Ref $1,4.3 .1$ ), then the approximate total yearly market for these devices can be conservatively estimated at:

( 100,000 people $/ 10$ people per house $) * 0.5$ stove per year $=5,000$ stoves $/$ year.

At the moment this is just a very rough estimate. It does not matter if in reality the real figure turns out to be double or half this figure, it is simply giving us a starting point from which to base further closer estimations which may well be based on proper sampling frames, statistical analysis and seasonal inputs such as potato and turnip prices.

An initial estimate of the device supply and demand 'map' may look something like figure 6 .

Many informal interviews conducted in Kalam by Wajid Syed indicated that the majority of Kalamis buy their devices from the Green Chowk, Mingora because they go shopping there anyway, and the quality and price of devices in Mingora is superior to elsewhere. If the same service was available in Kalam they would shop there.

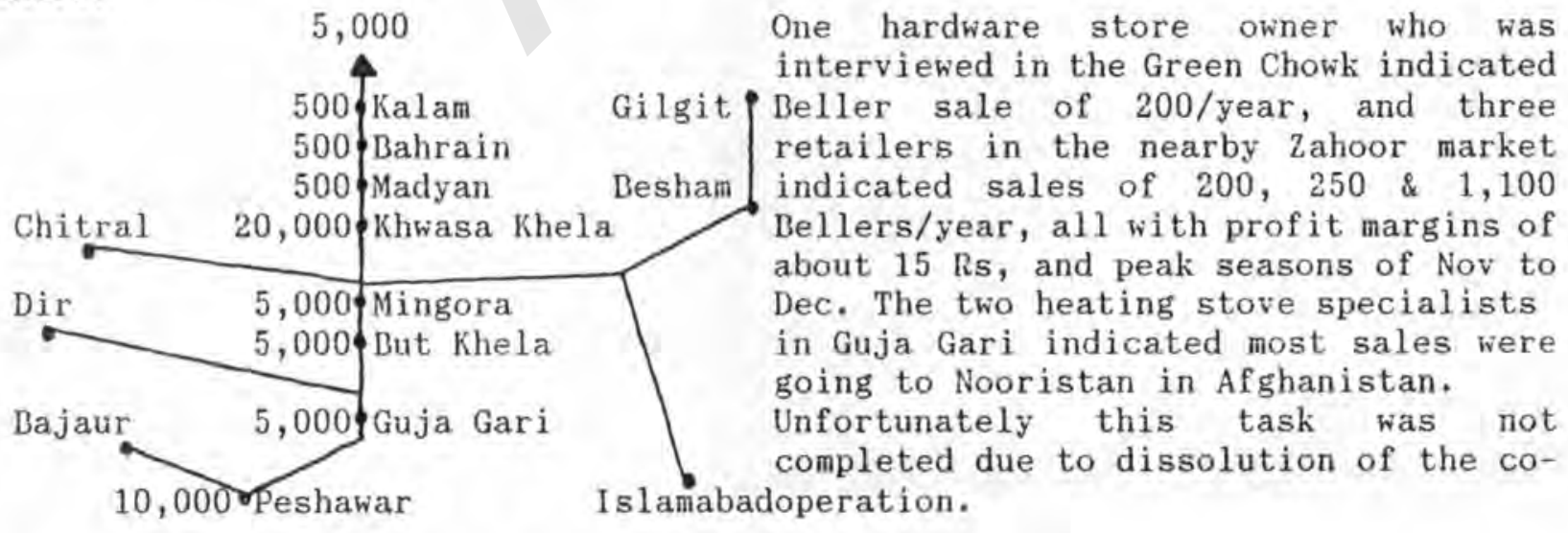

Pig 6: An initial estimate of the Swat Valley lleating Stove Supply\&Demand Map 


\section{Conclusions \& Recommendations}

\subsection{DEVICE TESTING}

Smoke testing with the hair dryer and filter papers in the laboratory was not very successful, possibly due to the three room changes. If it is to be tried in future it would be better to do all the smoke tests on one day, and to limit the test to burning a specified amount of wood (5kg?). The fuel type, chimney geometry and cleanliness should not change for the period of the tests as well. Furthermore the testing room needs to be ventilated slightly from a low point in the outside wall, atherwise all the readily available oxygen is used up and the fire goes out.

Carbon Monoxide testing in the field was extremely successful and easy to do. These tests should be limited to the one hour variety. The twenty second testa were only conducted here because of non availability of one hour test tubes,

Carbon Monoxide testing in the laboratory was unsuccessful due to the small range of the gas analyzer in use.

The $100 \mathrm{~kg}$ deformation and blocking test was found to be an excellent and necessary prelude to any device's test series, and it is strongly recommended that this practice be continued, although how many hours it takes to burn $100 \mathrm{~kg}$ of wood in a device was not very useful information. It's more important that the tester builds a large fire for as long as possible.

Cooking Performance testing methods were greatly enhanced by testing on the scales, thus providing a power versus pllu curve very quickly. Whilst the method of measuring the PIIU is not as accurate as the 'old' method, it provides many more points much more quickly, and it's lack of accuracy is more than compensated for. The tester should always remember to test the device over a wide range of power levels so that proper conclusions can be drawn. Furthermore, the results should be continuously compared to previous results to ascertain their authenticity.

Combustion Performance analysis is best done with a good gas analyzer and experienced operator, although there is nothing wrong with simply observing the color of the smoke as it leaves the chimney (A perspex chimey section may be an idea?). Again it is best performed whilst the device is on scales so that power and PIU is measured at the same time, but this is a difficult task that takes time to perfect. The electronic scales used in this series of experiments had a range of $30 \mathrm{~kg}$ in 1 gram gradations, and hence was very sensitive. In future it would be better if scales with a greater range $(100 \mathrm{~kg})$ and fewer gradations $(10 \mathrm{gm})$ could be found. Again, the tester should always remember to test the device over a wide range of power levels so that proper conclusions can be drawn.

Wood Consumption. $24 \mathrm{hr}$ fuel consumption tests before and after the introduction of the new device were extremely successful and should be continued. The questionnaire to assess the acceptability was possibly a bit long, but still very useful. A more informal open ended type interview is possibly better in this case, although this requires more experienced interviewers, and is more difficult to analyze. 


\subsection{DEVICE DESIGN}

Smoke Reduction. To reduce the smoke output is not too difficult if a few simple rules are followed:

1. Make sure the device won't deform. The $100 \mathrm{~kg}$ wood deformation and blocking. test is good for this. The device should be sufficiently tested in the laboratory anyway to ascertain its weak points.

To stop a device deforming make sure there are no large flat pieces of metal as in the bridge of the Zaher, or the internal baffle of the Jurgen B1 \& 2. Include bends and supports in the design. Reinforce the pot holes.

2. Make sure the geometry is correct. Basically this means ensuring the area of the exhaust passage is adequate to allow the gases for the fire to get to the chimney. This is easy to overlook in a heating stove designed to extract the maximum energy from the exhaust gases by using narrow passages.

Smoke production can be reduced even more if a good strong draught is created through the device. Unfortunately such a device is not conducive to reduced fuel consumption. Considering the fact that smoke reduction was a more important design criteria than reduced fuel consumption, all the new stove designs performed excellently in so far as demonstrating significant improvement over the traditional Beller. Smokey devices were successfully identified and eliminated in the laboratory before field testing (except for the Baris!).

The kinner in the smoke tests would have to be the $B$ series Jurgens, closely followed by the D series Bellers. All designers were quick to follow Jurgens lead in this field, and his ideas of pot hole reinforcing and a sliding door were fairly easy to implement in any design. The A \& B series Zahers were excellent in the smoke department in the beginning, possibly due to their better draught effect described above, but unfortunately the bridge in the A series was impossible to clean, and the chimney side of the pot hole was not reinforced sufficiently in the A or B series, and so with time it deformed and began to smoke at that point.

Price. Easily the cheapest 'new' device was the D series Deller. Next came the $B$ series Jurgen, followed by the Zaher A2. The Lexcen A2 would equal the D series Beller if the aluminium pot were excluded. The idea of using thinner gauge metal to reduce the price and the lifetime, can be applied to any device, however using various gauges of metal in one device is more applicable to some devices than others. The cost of the Jurgen in particular could be reduced by making the outer skin of thinner metal, and the inner baffle of thicker metal. Whichever device is chosen for mass dissemination, a marketable compromise regarding the gauge of metal to be used must be reached. Ilowever, whatever decision is reached, it is more than likely that the metal workers in the Bazaars, who have to make a profit on the new devices, will make up their own minds.

Wood Consumption. Unfortunately the only device that was tested properly in this regard was the Jurgen B3. More field testing is obviously required in this area.

Combustion. A good stove should facilitate complete combustion. All the Oxygen in the air should be used up, therefore the exhaust gas $\mathrm{O}_{i}$ concentration should be low while the $\mathrm{CO}_{2}$ concentration is high. Also, the excess air factor should 
be as low as possible otherwise the combustion process will be cooled down too much as in the B series Zahers. Frincipally good combustion is obtained by having the correct mix of primary and secondary air i,e, adequate primary air flow to make sure combustion is complete, and low enough secondary air flow to reduce the excess air ratio, and thus the cooling effect on the combustion process. Frimary air usually coms through a grate, whilst secondary air usually comes through the feeding door.

The issue of a grate is a moot point. Jurgen was of the opinion that a grate is not necessary in a heating stove because then all the fuel is used up and no coals are left to give of heat during the night, or to facilitate rekindling the fire (and possibly other reasons as well). One undeniable fact is that huge amounts of Carbon Monoxide are given of whilst a fire is smoldering (combustion is very incomplete), and this can be a problem to room inhabitants of a cheap leaky heating stove. Eng. Zaher was of the opinion that every heating stove in Afghanistan has a grate and was loathe to produce a version of the Zaher without one. Furthermore, the success of combustion in the Beller, which has a grate, is also undeniable. It appears that not having a grate is fine in a well sealed European device that will keep the harmful Carbon Monoxide inside whilst the fire is smoldering, but such a design is potentially very dangerous in the cheap type of stove that is being produced for the Kalamis.

A multipot style punched hole grate, as conceived by Jurgen, appears to be the best design provided there is the correct number of holes to allow the correct amount of primary air through, and that the holes are big enough to let the ash through, but small enough to stop the coals. The punched hole grate also provides a good bed of ash insulation which improves combustion and increases the lifetime of the device.

Too much secondary (excess) air was present in every device and needs to be reduced, but not so much that there is a shortage of air, although this is unlikely in the price range of stove being designed for the target population. In an attempt to reduce the volume of secondary and excess air (and smoke), Jurgen introduced the sliding door, and this appears to have worked well when comparing the general excess air ratios from devices with hinged doors, as opposed to those with sliding doors. It also has the added bonus of reducing the smoke output as well. Such a device is strongly recommended for any future heating stove.

The winner in terms of combustion was easily the Beller D3. It appears that this device had the correct mix of combustion chamber, door, grate and baffle size. It would be interesting to see the effect of a larger combustion chamber and sliding door on the ' $A$ ' series Zahers, or a grate on the ' $B$ ' series Jurgen. If a grate is to be introduced, it appears that the type used on the D series Beller is best i.e. punched hole, with sliding removable box underneath. The grate on the Zaher was more expensive, required the stove to be taken outside to be cleaned, and appeared to have little effect unless the grate door was open, which is not usually the practice of the target population.

One area that was not investigated was insulation of the combustion chamber (with a mud liner filled after the device is installed?), although the Jurgen was inherently insulated by virtue of it's two side channels. 
lleating, A good metal heating stove will invariably have a long narrow channel at some point or other. The Zaher has the bridge, and the Jurgen has the two side passages, whereas the Beller is missing such a feature. This passage needs to be as narrow as possible, but not so narrow that it blocks too quickly. If it does block, it needs to be cleanable, unlike the Zaher A2. It must also have sufficient cross sectional area to allow the exhaust gases out (see rule 2 of smoke reduction above).

The excess air factor should also be kept low, otherwise cold air will simply carry the hot exhaust gases up the chimney (and also cool down the combustion process).

The winner in the heating field was undoubtedly the Jurgen B3 due to it's moderate combustion performance combined with excellent heat extraction properties. The difference in performance between the JB2 and the JB3 was quite incredible for such a small design change. The Zahers appeared to have even better heat extraction potential but failed due to such a small combustion chamber in the A series, and poor combustion occurring in the B series, which was possibly due to the removal of the grate.

Water tanks were a 'hot' issue. KIDP staff were generally against them because of their added cost, and that's why GTz came up with the chimney water tank as an optional extra. These were extremely popular with the housewives who bought them (at a subsidized price!) due to the vastly increased household cleaning possibilities such a device presented to them. Obviously a water tank presents many advantages to a heating stove designer as well from the point of view heat energy storage and transfer, and many disadvantages from the point of view of cost and corrosion. Obviously no firm conclusions could be drawn from the exercises described in this report. The debate will continue.

Useability. All the devices were good from a user point of view. The sliding door, once the design was perfected, was seen as an excellent modification from the smoke reduction and useability point of view i,e. no one complained about it, and none were observed to be jammed during the field testing. The removable ash tray in the Beller was also a very good innovation. No one appeared to mind that the Jurgen had only one pot hole. Designers of stoves for the Kalam area must always keep in mind the local habit of slowly feeding large uncut logs into the combustion chamber. This was obviously well accommodated in the Bellers and Jurgens, but the combustion chamber and feeding door in the Zaher was generally found to be too small and difficult to feed large logs into. The baking tray in the Zaher was not found to be a worthwile improvement either. Chimney flaps were invariably not used, removed or got jammed and blocked the exhaust gas flow. Moving parts are not a good idea in these types of devices. 


\section{References}

1. "Assessment study concerning the potential for starting domestic fuel saving activities by KIDP", Peshawar \& Kalam, Pakistan, June 1990; Kalam Integrated Development. Project (KIDP), Domestic Energy Saving Project (DESP).

2. "A Proposal for Co-Operation between FECT \& KIDP (Version 1,2i3)", by Stephen Lansell \& Wajid Syed, 21 April, 1991, GTZ-FECT, Peshawar, Fakistan.

3. "Research and Design of Cooking and lleating Devices" by Stephen Lansell, GTZ-FECT, Peshawar, Pakistan, March 1991.

4. "Technical Section Research Report 1990 " by Martina Nintemann, GTz DESF \& FECT.

5. "One day monitoring of the devices disseminated in Kalam, on the 23rd of April 1991" by Wajid Syed, GTZ-FECT.

6. "Report on meeting with Representatives from Kalam" by Wajid Syed, January 1991, GTZ-FECT.

7. "Assessment of the Zahir A2 stove by llabib Khan after 5 days use" by Dietlinde Warth, CTA of KIDP, December, 1990.

8. "Phase III of the Field Test on the Jurgen B3" by Wajid Syed, GTZ-FECT, Pebruary 1991.

9. "Report on installed base in Kalam device wise" by Wajid Syed, GTZ-FECT, February, 1991. 
APPENDIX 1: Beller Laboratory Test Results (Sorted on Power)

\begin{tabular}{|c|c|c|c|c|c|c|c|c|c|c|c|c|}
\hline Device & Name & Test & Pwr & PIIU1 & PIIU2 & Chim & 02 & $\mathrm{qA}$ & 1 & $\mathrm{CO} 2$ & Room & Temp \\
\hline Beller & A1 & 9 & 10 & 8 & & 91 & & & & & & \\
\hline Beller & A1 & 1 & 11 & 8 & & 514 & & & & & & \\
\hline Beller & A1 & 7 & 11 & 13 & & 594 & & & & & & \\
\hline Beller & A1 & 8 & 13 & 10 & & 528 & & & & & & \\
\hline Beller & A1 & 4 & 13 & 35 & & 497 & & & & & & \\
\hline Beller & $\mathrm{A} 1$ & 3 & 14 & 16 & & 464 & & & & & & \\
\hline Beller & $A 1$ & 11 & 14 & 3 & & 447 & & & & & 1 & 11 \\
\hline Beller & A1 & 12 & 15 & 5 & & 484 & & & & & 1 & 10 \\
\hline Beller & A1 & 5 & 15 & 27 & & 550 & & & & & & \\
\hline Beller & A1 & 6 & 17 & 17 & & 630 & & & & & & \\
\hline Beller & $\mathrm{A} 1$ & 10 & 18 & 6 & & 166 & & & & & & \\
\hline Beller & A1 & 13 & 19 & 11 & 4 & 490 & 11 & 36 & 2.1 & 9.9 & 3 & 14 \\
\hline Beller & A1 & 2 & 21 & 5 & & 580 & & & & & & \\
\hline Beller & $\mathrm{A} 2$ & 3 & 7 & 13 & & 140 & & & & & & \\
\hline Beller & $\mathrm{A} 2$ & 12 & 7 & 13 & & 155 & & & & & & \\
\hline Beller & $\mathrm{A} 2$ & 6 & 8 & 14 & & 556 & & & & & & \\
\hline Beller & $\mathrm{A} 2$ & 7 & 9 & 11 & & 498 & & & & & & \\
\hline Beller & A2 & 10 & 9 & 2 & & 532 & & & & & & \\
\hline Beller & $\mathrm{A} 2$ & 2 & 9 & 8 & & 518 & & & & & & \\
\hline Beller & A2 & 9 & 10 & 9 & & 568 & & & & & & \\
\hline Beller & $\mathrm{A} 2$ & 11 & 12 & 15 & & 599 & & & & & & \\
\hline Beller & $\mathrm{A} 2$ & 5 & 12 & 8 & & 484 & & & & & & \\
\hline Beller & $\mathrm{A} 2$ & 4 & 14 & 8 & & 549 & & & & & & \\
\hline Beller & A2 & 8 & 14 & 13 & & 702 & & 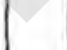 & & & & \\
\hline Beller & A3 & 2 & 9 & 13 & & 348 & 14 & 44 & 3.8 & 5.7 & 3 & 15 \\
\hline Beller & A3 & 1 & 25 & 7 & & 602 & 7 & 34 & 1.6 & 12.9 & 3 & 17 \\
\hline Beller & $\mathrm{C} 1$ & 4 & 7 & 18 & & 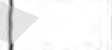 & & & & & & \\
\hline Beller & $\mathrm{C} 1$ & 3 & 13 & 7 & & 119 & & & & & & \\
\hline Beller & C1 & 1 & 13 & 9 & & 122 & & & & & & \\
\hline Beller & $\mathrm{C} 1$ & 2 & 21 & 6 & & 98 & & & & & & \\
\hline Beller & D1 & 1 & & & & 362 & & & & & 1 & 14 \\
\hline Beller & D2 & 1 & & & & & & & & & & \\
\hline Beller & D2 & 3 & 5 & 22 & & & & & & & & \\
\hline Beller & $\mathrm{D} 2$ & 6 & 5 & 17 & & 652 & & & & & & \\
\hline Beller & D2 & 5 & 6 & 11 & & & & & & & & \\
\hline Beller & D2 & 7 & 6 & 13 & & & & & & & & \\
\hline Beller & D2 & 2 & 6 & 20 & & & & & & & & \\
\hline Beller & D2 & 4 & 7 & 12 & & & & & & & & \\
\hline Beller & D2 & 9 & 16 & 13 & & 562 & 7 & 30 & 1.5 & 13.6 & 3 & 14 \\
\hline Beller & D3 & 2 & 11 & 16 & 4 & 464 & 7 & 25 & 1.7 & 13.1 & 3 & 9 \\
\hline Beller & D3 & 1 & 11 & 18 & 5 & 436 & 10 & 30 & 1.9 & 10.9 & 3 & 10 \\
\hline
\end{tabular}


APPENDIX 2: Laboratory Test Results (Sorted on Power)

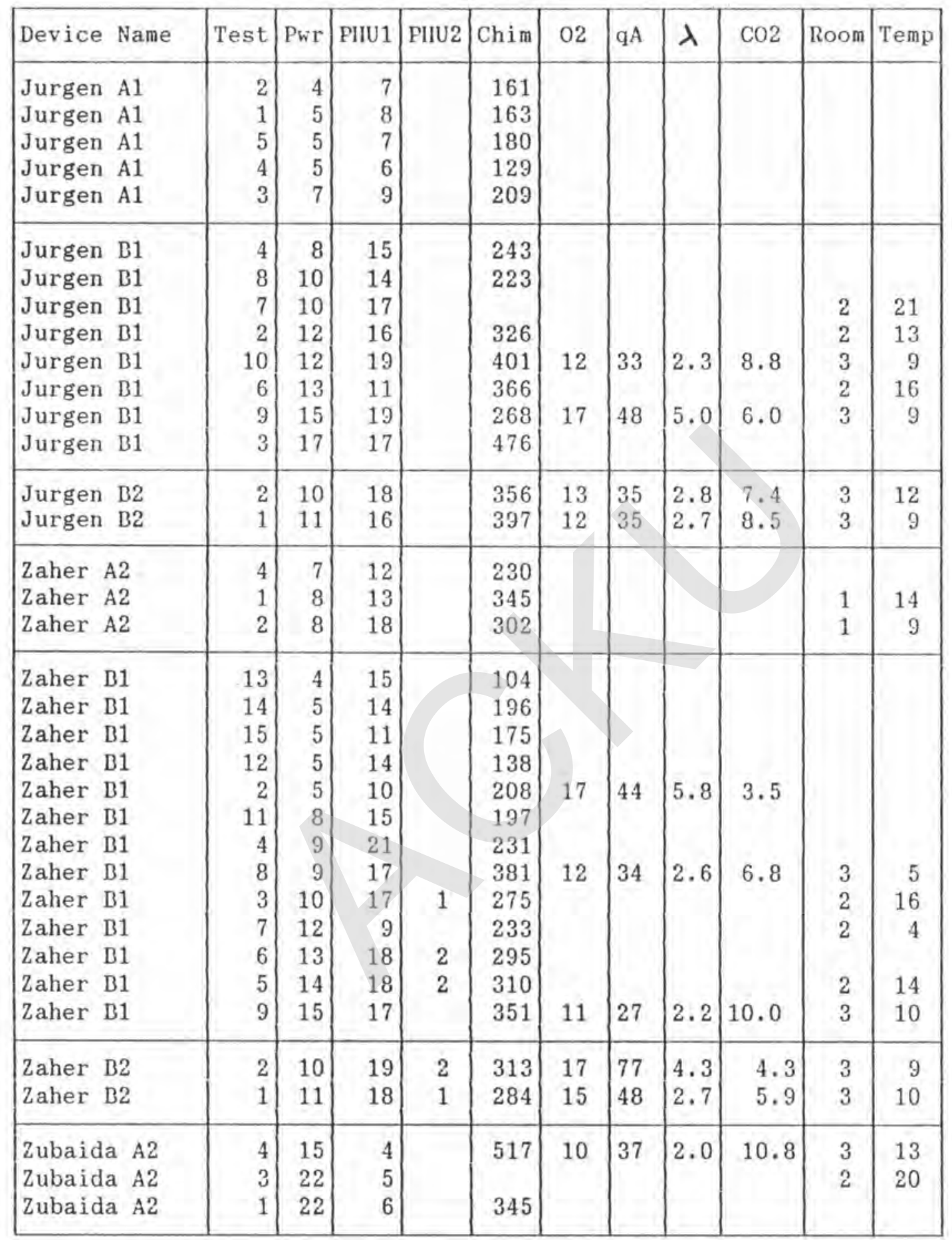




\section{APPENDIX 3: Filter Paper Tests}

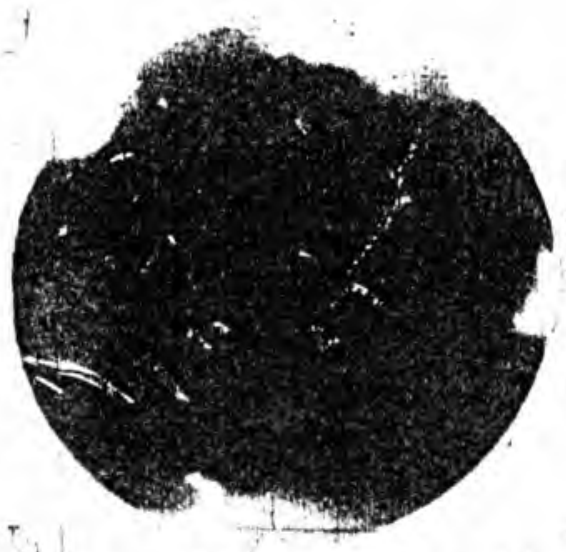

Stove: Bether-pH -1 Date: 2 lid 78 Duration: 60 min Room: I Haid weed.

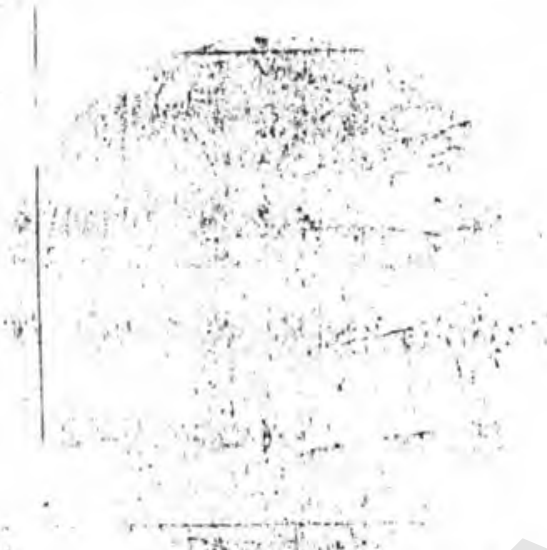

Stove: Buller-A 3/1 Date: 27-1-1| Duration: 60 min Room: 3

Stove: Beller.02-1 Date: Duration: lecin soft weod.
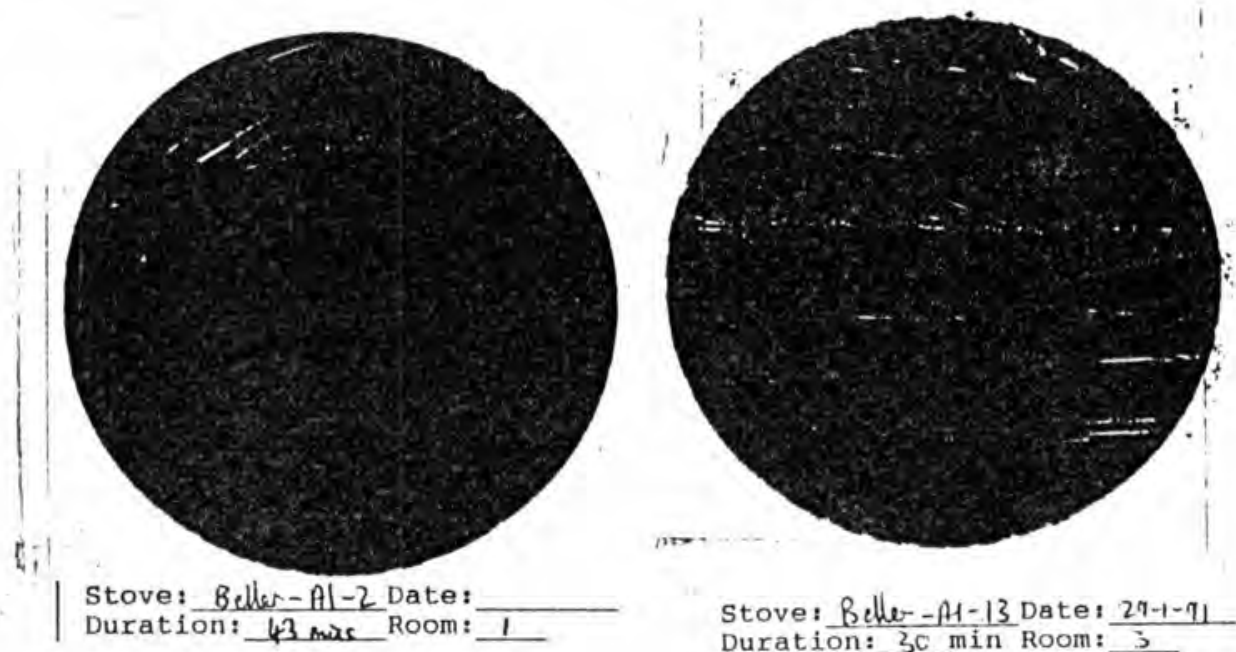

Stove: Bether-M1-13 Date: 29-1-71 Duration: $3 \mathrm{C}$ min Room:

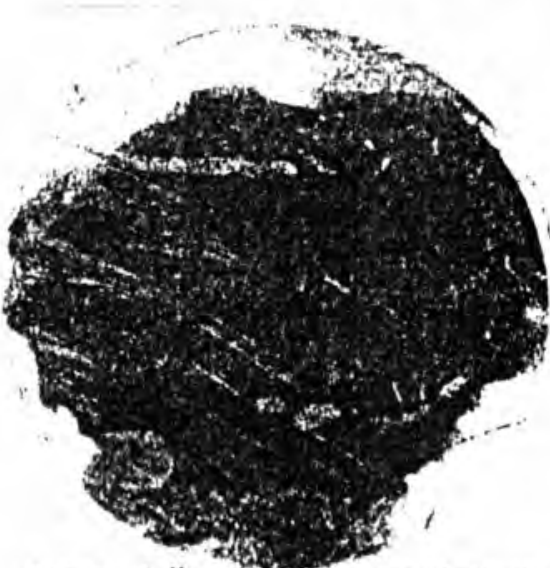

Stove: Bellen aDate: $78-10 \cdot 40$

Stove: Beller $-03 / 2$ Date: $25-1-91$ Duration: $6.0 \mathrm{mi}$ Room: 3 softwood.

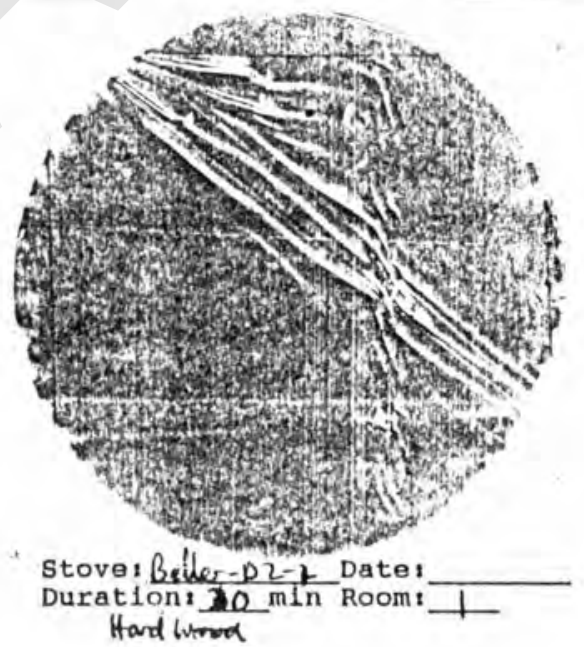

Stove: Bella-Dz-q_Date: $24-1-9 \mid$ Duration! $60 \mathrm{mi}$ Room: 3 
Stove : $Z$ AHAYR-A-2-JDate: $22-10^{\circ}-90$ Duration: $60 \mathrm{~min}$ Room: $\frac{1}{1}$

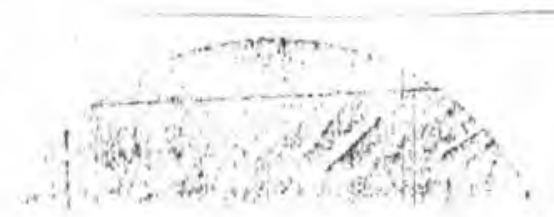

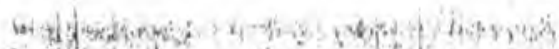

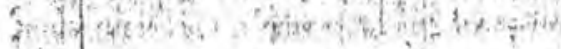

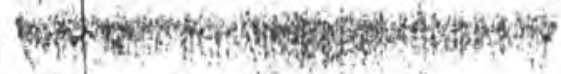

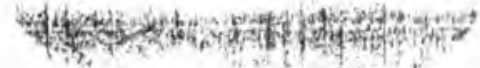

Stove $Z$ AHIRB $1-3$
Duration: $\frac{60}{60}$ Room: $\frac{15-1-91}{2}$ $\overline{\Delta W 1.3 n_{q}}$

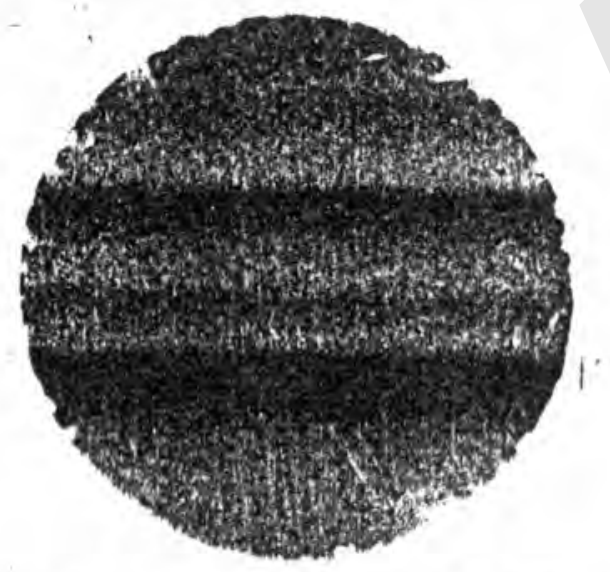

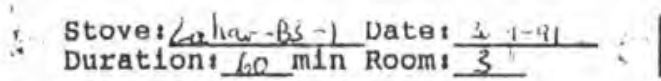

Stove : ZAHAIR.A-22pate: 2.9110190 Duration: $\perp$ bo Room:

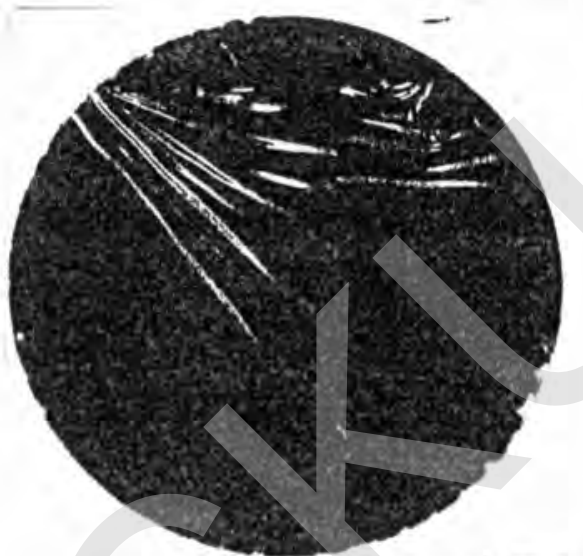

Stove: $\geq$ AHIR B1-5 Date: $15-1-91$ Duration: $\frac{60 \mathrm{~min} \text { Room }}{\Delta \omega}=2 \cdot 8 \mathrm{mg}$

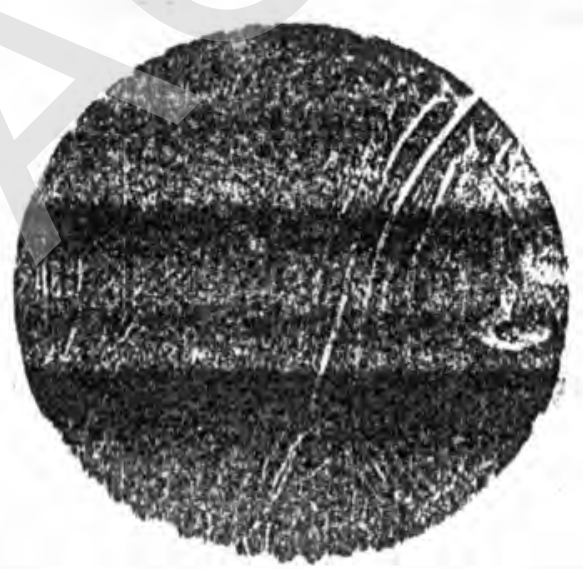

Stove: Lahum -63 L Date: $\frac{30}{3}$ il
Durations $60 \mathrm{~min}$ Room:

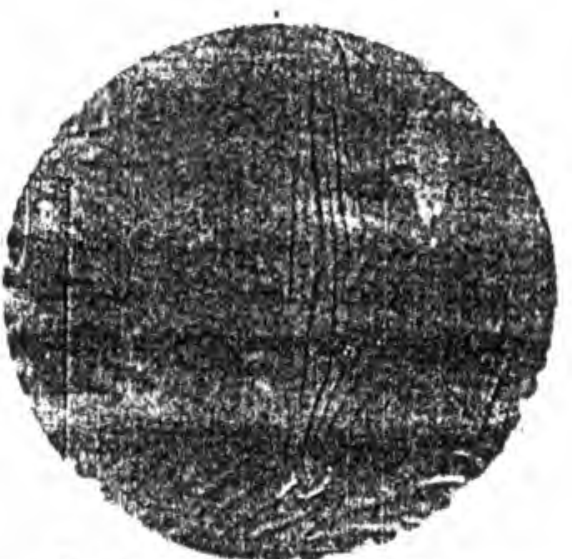

Stove: $Z$ AHERßI-1Date: Duration: 60 min Room:

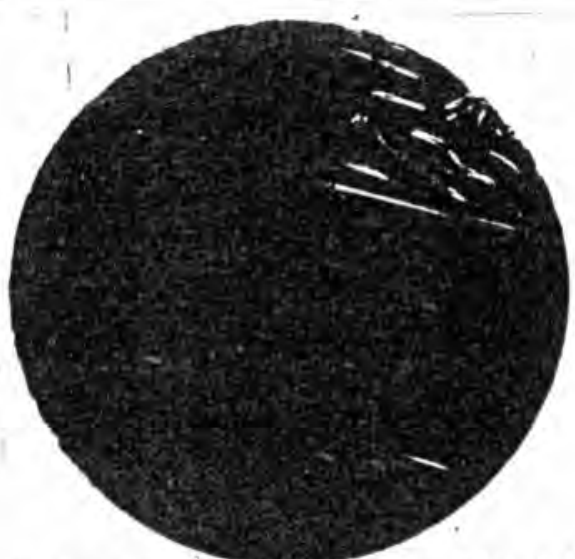

Stove: 2 Aher $-B \mid-9$ Date: $\frac{24-1-C}{3}$
Duration: 60 Room: $\Delta w=1.83 \mathrm{mg}$

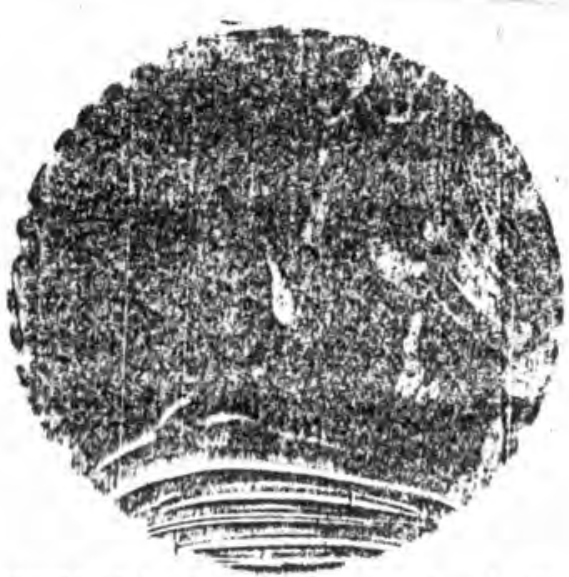

Stove: ZubaidaA24Date: $23-1-71$ Duration: 60 $\Delta \Delta_{i}=1.0 S^{\prime}$ 

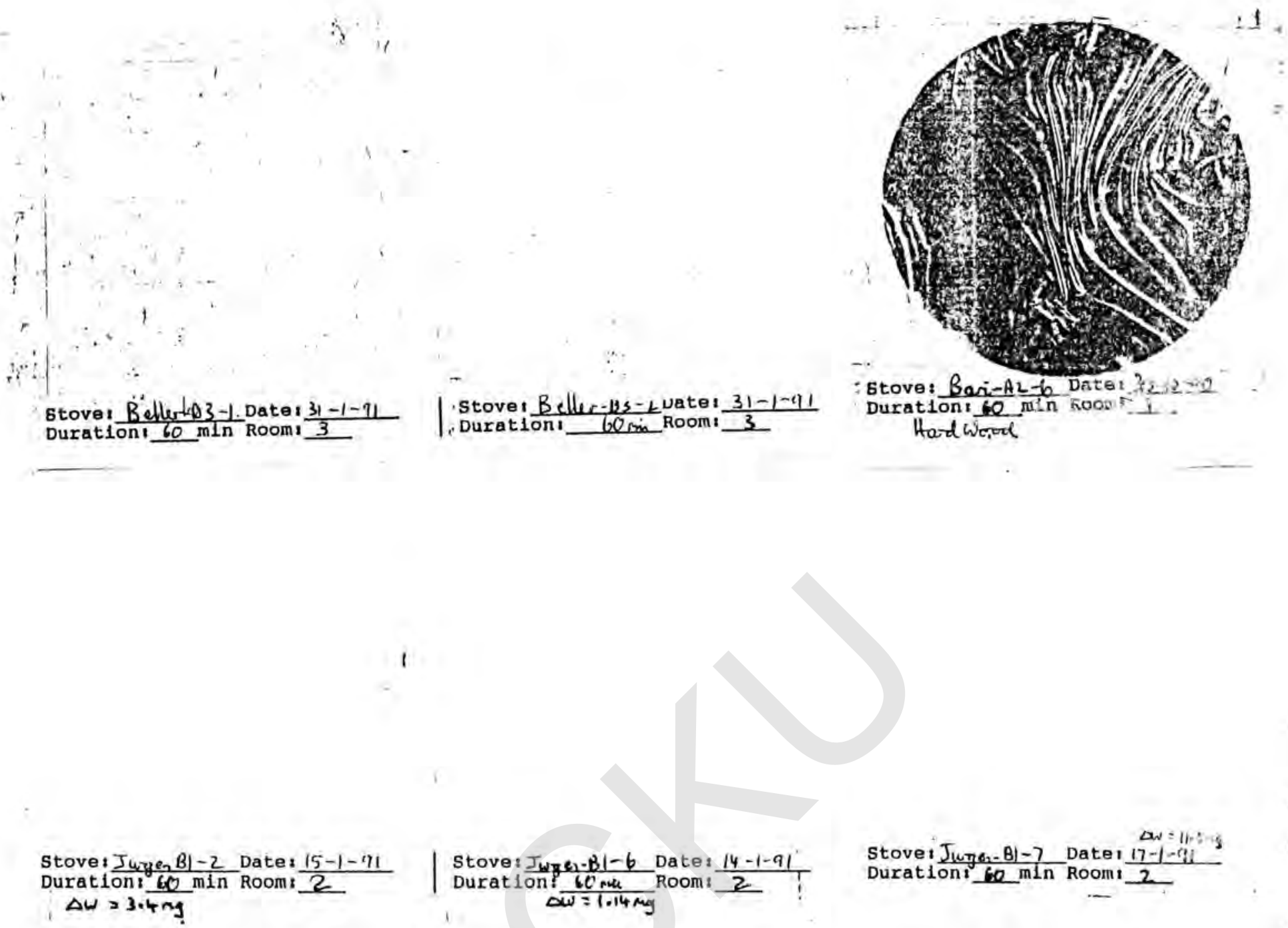

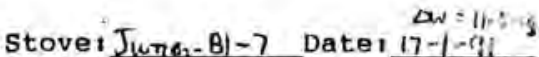
Duration $60 \mathrm{~min}$ Roomi $\frac{7}{2}$ $\Delta w=3.4 n g$
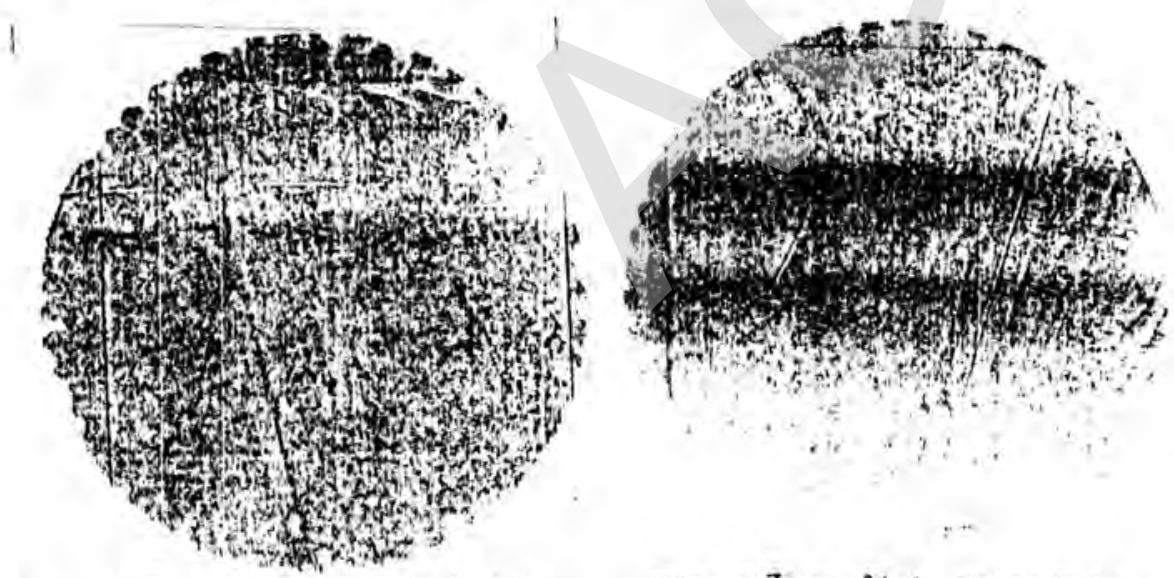

Stove: Juga BI-q Date? $21-|-q|$ Duration? 32 mis

Stove: Jhiz, BL-1 Date: $12-1-91$ Duration: $10 \mathrm{~min}$ Room: 3 Resi. Woed.
Sluve: Jivqu RL. 2 Date: $281-71$ Duration: $10 \mathrm{mi}$ noom: $\frac{3}{3}$ 
Test-No: 5 .

Name of Device Jurgen $B-3$ Date $9 / 3 / 91$ Time $1: 30 P M$.

1.Name of the guide_Mr. Rooh-Ullah.

\section{DETAILS OF THE HOUSEHOLD}

2. Name of the head of the family_Mr. Zabib-Ur-Rehman.

3. Name of the person interviewed : Mr. Zabib-Ur-Rehman.

4. Address:Village Jalband, Kalam.

5. No, of Adults: 2 6. No. of Children: 4

7. Source of income of the family: Head of the family is a teacher. in Kalam Primary School, Also he has aggricultural land of about 2.5 Kanals.

8. If more than one Bread earner give details: N.A

9. Do you keep domestic animals $(Y / N)$, if yes give details: N.A

10. Design of the house:

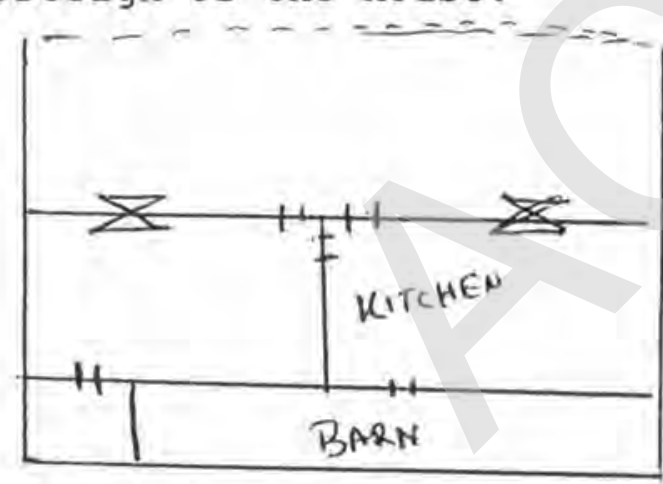

$$
\begin{aligned}
Z & =\text { Mindow } \\
H & =\text { Doov. } \\
& =\text { No wist with vort }
\end{aligned}
$$

11. Material used for the construction of the house: Wood, Stones and Mud Plastering. Constructed in $1982+$

12. Site Location of the house: Taraced. Siyle story

13.Size of kitchen : Length/Breath/Height: 176 "X180"X194.5"

14. No. of windows in the kitchen:One with two doors plus vantelator with window pane on top of the window.

Size of windows : Each door (18"X46") Vantelator (16.5"X 38.5") 
15. No. of doors in the kitchen : Three. One towards out side, Two towards each of the rooms.

15/a.Size of doors: Door $1=72.5^{\prime \prime} \times 42^{\prime \prime}$, Door 2=70"X25", Door $3=71 " \times 32 "$.

16. Duration of time Doors kept open: 10 to 15 minutes in an hour.

17. Reasons for keeping it open: For smoke exhaust, as wellas light.

18. Sources of light in the room: If the day is too cloudy we keep the door open, other wise we use the windows.

\section{OLD DEVICE/S DETAILS}

30. Number of old devices: Two, one in barn, other in kitchen cum bed room.

30. Description of the traditional device/s: Traditional Round beller in the kitchen \& traditional heating drum shaped in the kitchen.

31.Price of old device/s:240/- for kitchen from Gujar Gari. $100 /$ - for barn made of coaltar drums Rs

32. Condition of old device/s: Quite good.

33. One or two pot holes: Two, one in the other just like J-B3

34. Date of purchase of the device/s : Both two years ago.

35. Location of the device in the Room: Two Feets from wall No 4.

36. Details of its installation in the room i.e Mud etc: In mud.

37. Daily operation cycle:

Summer: Device is used for cooking only that too in the varandah.

b/ Winter: From morning prayers call to 9:00 PM in the evening.

\section{CHIMNEY DETAILS}

40.Length of the chimney: 194.5 " 
41 Circumfrance of the chimney: $13.5^{\prime \prime}$

42. Height of the chimney above the roof: 7 "

43. Geometry of the chimney: Goes out of the side of the devite and bends at 90 degrees after running straight for three 3 "

44. Are the chimnies cleaned(Y/N)_Y If yes how often: Orce week in $w$.

45. Method of cleaning: with a pullthrough.

46. Do the chimines block $(\mathrm{Y} / \mathrm{N})$ if yes when: N/A

47. Do you need flaps $(\mathrm{Y} / \mathrm{N})$ if yes reasons: No, the consept 1 , not clear.

48. Is any body using open fire $(Y / N)$ if yes any information: $N / A$

\section{DETAILS OF THE FUEL SUPPLY}

60. Kind of wood: Diyar.

61. Source of wood: Cut in our forest and brought to the house in a truck.

62. Who splits the wood: Head of the family.

63. Do you use any other kind of fuel(Y/N) if yes which kind_N/A

64. Which kind of wood they prefer :Diyar.

65. Approximate size of logs:

66. Distance of wood source from house: two hours and thirty minutes wa in the snow.

67. Where is the fuel wood stored: In the varandah.

68. How much wood is consumed per year:At least one truck.

69. Moisture Contents 1)_14.3

2) $-13 \cdot 1$

3) -17.5 
80. Details of Pots/Pans/Tawas used for cooking: One cooking pot and a clay tawa. The clay tawa has a $13^{\prime \prime}$ radius. Pot is 12 " in radius.

81. Describe the PRIMARY Pots

82. Discription of pots used during 24 hours:

83. Brief discription of their daily eating habits : Tea cooked in the morning, afternoon and evening, curry cooked once a day, bread cooked in the afternoon and evening, in breakfast the bread from other day is consumed.

84. No. of times stove used for cooking 6 .
a) Curry _once
b) Bread
Twice
c) Tea_Thrice
d) Miscellaneous
$-\mathrm{N} / \mathrm{A}$

85. Source of water: In winter we drink water from the streem and in summers we drink water from the spring.

86. Need Hot water $(\mathrm{Y} / \mathrm{N})$-Yes

87, Feel need for hot water tank ( $Y / N)$, If yes what size: For normal use we place a pot on top of the device, for washing clothes we heat water in large ghee tin twice a month. Yes we need a hot water tank but at no additional price.

88. Duration of time stove used for purely heating : From morning prayers call to 9:00 PM. in the evening.

89. For how long do you heat the room ? From mid october to end april.

101. No of Hrs/day for heating : _ In winters as in Ans. 88

102. Do you feel the device is too expansive? Yes

103. Do you feel the new device is more difficult to start:

No,

104 Do you feel the new device is more difficult to operate:

No.

\section{TEST DETAILS}

90. Do you feel the new device produces more smoke? No. 
91 Do you feel the new device produces less heat?

92. Lo you feel the new device cooks food slower?

93. Do you feel the new device uses more wood?

94. Do you feel the new device will not last very long:

Initial Wood $\mathrm{Kg}$ Final wood $\mathrm{Kg}$ Difference

Original Device 42 6 36

New Device 47 13 34

\section{ROOM DETAILS}

Date Time Fire Size Room Temp Smoke Rating (1-10) Co Level

9/4_1:45_Med. 12/4_5:00_Med. 18 16

9
15 0

On the 9 th all the doors and windows were closed for 15 minutes and the $\mathrm{CO}$ and smoke were recorded. On the 12 th the doors and windows were closed for 25 minutes and the $\mathrm{CO}$ \& smoke readings were taken. On the 12 th Cta KIDP also accompnied me.

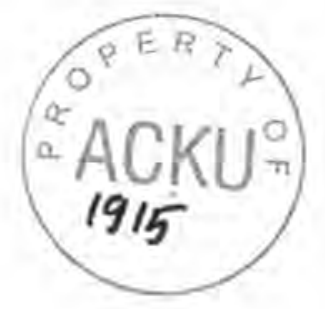

